\title{
Lineage-Specific Functionality of an Interferon Regulatory Factor 5 Lupus Risk Haplotype: Lack of B Cell Intrinsic Effects
}

\author{
Justine Calise ${ }^{1,2}$, Susana Marquez Renteria ${ }^{3}$, Peter K. Gregersen ${ }^{3}$ and Betty Diamond ${ }^{2 *}$ \\ ${ }^{1}$ PhD Program in Molecular Medicine, Donald and Barbara Zucker School of Medicine at Hofstra-Northwell, Hempstead, NY, \\ United States, ${ }^{2}$ Laboratory of Autoimmune \& Musculoskeletal Diseases, The Feinstein Institute for Medical Research, Center \\ for Autoimmune, Musculoskeletal, and Hematopoietic Diseases, Northwell Health, Manhasset, NY, United States, \\ ${ }^{3}$ Laboratory of Genomics \& Human Genetics, The Feinstein Institute for Medical Research, Center for Genomics and \\ Human Genetics, Northwell Health, Manhasset, NY, United States
}

OPEN ACCESS

Edited by:

George C. Tsokos, Harvard Medical School,

United States

Reviewed by:

Stamatis-Nick C. Liossis, University of Patras, Greece Esra Meidan,

Harvard University, United States

*Correspondence: Betty Diamond bdiamond@northwell.edu

Specialty section: This article was submitted to B Cell Biology, a section of the journal Frontiers in Immunology

Received: 27 March 2018 Accepted: 23 April 2018 Published: 07 May 2018

Citation:

Calise J, Marquez Renteria S, Gregersen PK and Diamond B (2018) Lineage-Specific Functionality of an Interferon Regulatory Factor 5 Lupus

Risk Haplotype: Lack of B Cell Intrinsic Effects.

Front. Immunol. 9:996. doi: 10.3389/fimmu.2018.00996
Interferon regulatory factor 5 (IRF5) is widely recognized as a risk locus for systemic lupus erythematosus (SLE). Risk gene and IRF5 activation is triggered through toll-like receptor signaling. In myeloid cells, this leads to production of type I interferon and inflammatory cytokines, with enhanced production in cells of individuals harboring IRF5 risk alleles. Mouse models have also demonstrated the importance of IRF5 in B cell function, particularly plasma cell differentiation and isotype switching. Here, we evaluated the major SLE risk haplotype of IRF5 on the functional attributes of freshly isolated B cells from human subjects who do not have evidence of SLE or other forms of autoimmunity. We took this approach to avoid the complications of studying genotype-phenotype relationships in B cells that have been chronically exposed to an inflammatory disease environment before isolation. We focused on B cell endophenotypes that included gene expression, antibody secretion, class switching, and apoptotic susceptibility. We performed IRF5 overexpression studies, genetic reporter assays and electro-mobility shift assays on $B$ and myeloid cell lines. Somewhat surprisingly, the results of our analyses indicate that IRF5 risk genotypes do not have a B cell intrinsic effect on these B cell functions. By contrast, we confirmed that the IRF5 risk and non-risk haplotypes exert differential effects in myeloid cells, including an increased susceptibility to apoptosis conferred by the risk haplotype. We also demonstrated an increased binding of the transcription factor specificity protein 1 to an insertion/deletion present in the risk haplotype. Our findings raise the specter that genetic risk alleles can have complex and unexpected lineage-specific effects, and these must be carefully considered when guiding or developing therapies based on understanding disease risk haplotypes.

\section{Keywords: genetics, B lymphocytes, monocytes, haplotypes, autoimmunity, lupus}

\section{INTRODUCTION}

Systemic lupus erythematosus (SLE) is an autoimmune disease characterized by a breach in B cell tolerance to self-antigens. Genetic, hormonal, and environmental factors contribute to susceptibility to SLE. The transcription factor interferon regulatory factor 5 (IRF5) is one of approximately 100 genes with SLE-associated risk variants $(1,2)$. Within the immune system, IRF5 is expressed in myeloid cells and lymphocytes (3-5). IRF5 has diverse roles in myeloid cells including production of interferon- $\alpha$ 
(IFN $\alpha$ ) and other proinflammatory cytokines (6), regulation of the cell cycle and apoptosis (7), macrophage polarization (3), and metabolism (8). IRF5 can be activated by toll-like receptor (TLR) agonists, including nucleic acid-containing immune complexes present in SLE. IFN $\alpha$ can contribute to B cell autoreactivity seen in SLE. Many SLE patients have elevated levels of serum IFN $\alpha$ and markedly increased expression of interferon-inducible genes (9-12). Prior studies have shown that SLE-associated risk alleles of IRF5 display increased expression in myeloid cells and influence monocyte and macrophage activation $(8,13,14)$.

IRF5 has direct effects on B cells as well. IRF5 has been shown to be critical for terminal B cell differentiation to plasma cells in mice $(15,16)$. IRF5 also plays a role in isotype switching to IgG. Irf5 $5^{-/}$mice have increased levels of IgG1 and decreased levels of IgG2c (17). IRF5 has been shown to directly regulate transcription of the $\gamma 2$ a locus; $I r f 5^{-/-}$mice do not produce IgG 2 a antibodies (18). There is evidence that IRF5 is necessary for SLE development based on studies of pristane-treated C57BL6 Irf5 $5^{-/-}$ and MRL/lpr Irf5 $5^{-/}$mice. The former lack antinuclear antibody (ANA) titers and glomerular deposits of immune complexes after pristane challenge (18). The latter survive longer, exhibit milder glomerulonephritis and lower ANA titers $(16,19)$ than IRF5 sufficient MRL/lpr mice. Consistent with a contribution of IRF5 to autoimmunity, and a contribution of lupus-like inflammation to IRF5 expression, the autoimmune C57BL/6.Nba2, NZB/W, and Sle123 mouse strains all exhibit increased expression of IRF5 in splenic cells compared with C57BL/6 mice (20).

$\mathrm{Fc} \gamma \mathrm{RIIb}$ is known to protect against autoantibody production $(21,22)$. When bound to IgG immune complexes and co-ligated to the BCR, FcyRIIb initiates an inhibitory signaling cascade, mediated through its immunoreceptor tyrosine-based inhibitory (ITIM) motif $(22,23)$. In mice, a reciprocal regulation of IRF5 and Fc $\gamma$ RIIb has been reported (20). Fc $\gamma$ RIIb is important for B cell tolerance by setting a cellular activation threshold. C57BL6.Nba2 mice develop a lupus-like phenotype due to the presence of the Nba2 locus (24). C57BL6.Nba2 Irf5 ${ }^{-/}$mice exhibit increased expression of FcyRIIb and C57BL6 Fcgr2b-/- mice exhibit increased expression of IRF5 (20), suggesting reciprocal regulation of IRF5 and Fc $\gamma$ RIIb.

Located on chromosome 7 in humans, IRF5 has a total of 12 exons. Exons $2-8$ and part of 9 are coding. Exon 1 is subdivided into four non-coding exons 1a-1d (25). Each noncoding exon corresponds to a different promoter (26), allowing alternative splicing of the gene. There are over 100 known polymorphisms of IRF5, but only four are thought to be functional (27). Three of these polymorphisms are located in non-coding regions of IRF5. The non-coding polymorphisms rs142738614, rs2004640, and rs10954213, are located between exons 1d and $1 \mathrm{a}$, in exon $1 \mathrm{~b}$, and in the polyA tail of exon 9 , respectively. The three alleles have been reported to be in linkage disequilibrium (LD) (13). The fourth polymorphism is a $30 \mathrm{bp}$ insertion/deletion (indel) located in exon 6, and inherited independently of the three SNPs.

The "T" risk allele of SNP rs2004640 is located in exon 1b and introduces a donor RNA splice site, enabling expression of mRNAs containing exon $1 \mathrm{~b}(2)$. Exon $1 \mathrm{~b}$ transcripts are not translated into protein (28) and are expressed at very low levels compared with exon 1a transcripts (29), so the functional significance of rs2004640 is not entirely clear. The "A" risk allele of the SNP rs10954213 in the 3' UTR of exon 9 introduces a more proximal polyA site. This allele has been shown to confer increased expression as well as greater mRNA stability likely due to decreased susceptibility to degradation of the shorter transcripts $(30,31)$. The polymorphism rs 142738614 is an indel located $64 \mathrm{bp}$ upstream of exon 1a that refers to the number of copies of the 5 bp sequence CGGGG; the risk allele has four copies which introduces an additional binding site for the transcription factor specificity protein 1 (SP1) $(26,32)$. To date, the functional impact of this additional SP1 binding site in predisposition to SLE is unknown.

Currently, data available on the effects of IRF5 risk alleles in human B cells are rather limited. In contrast to previous reports, using cell lines or B cells of SLE patients $(2,33)$, we demonstrate that in healthy donors, the IRF5 risk and non-risk haplotypes are not differentially expressed in B cells in the resting state or after TLR activation. In addition, IRF5 haplotypes do not differentially regulate $B$ cell differentiation to antibody-secreting cells (ASCs) or IRF5-mediated apoptosis, and that IRF5 does not regulate Fc $\gamma$ RIIb expression in human B cells. Our findings confirm that these same IRF5 risk haplotypes do exert differential effects in myeloid cells and demonstrate that the $4 \times$ CGGGG indel is a potential causal allele in this context. Thus, we conclude that IRF5 acts indirectly on B cells through B cell extrinsic pathways. These data underscore the importance of examining multiple cell types when studying risk haplotypes in complex diseases. Moreover, they clearly demonstrate that the observation that a gene is important in the function of a particular cell type (e.g., the importance of IR5 in B cell function) does not necessarily imply that disease-associated haplotypes will display differential effects intrinsic to that cell type.

\section{MATERIALS AND METHODS}

\section{Study Subjects and Study Approval}

Study participants came from the Genotype and Phenotype Registry (GAP) registry at the Feinstein Institute. Their ancestry was European (EUR), African (AFR), Hispanic/Latino, South Asian (SAS), West Asian, or any combination of these. Subjects included premenopausal females and age-matched males, from 18 to 50 years of age. All subjects included in the study were homozygous risk or homozygous non-risk for IRF5, without autoimmune disease and not on corticosteroids, chemotherapeutic or cytotoxic drugs, or selective cell depletion therapies, thereby allowing us to study effects of the risk haplotype independent of the effects of disease or medications. The study was approved by the Institutional Review Board at the Feinstein Institute for Medical Research. Prior written consent was received from all study participants.

\section{IRF5 Haplotype Assembly}

Phase 3 genetic data for the IRF5 locus on chromosome 7 were extracted from the 1000 Genomes Project browser ${ }^{1}$ for the

${ }^{1}$ www.internationalgenome.org (Accessed: July, 2017). 
following populations: AFR, African; AMR, American/Hispanic/ Latino; EAS, East Asian; EUR, European; SAS, South Asian. Haplotype maps were constructed for each population using Haploview software. Genotyping for representative variants (see Genotyping) was performed on subjects in the GAP. ${ }^{2}$

\section{Genotyping}

We confirmed the LD of rs142738614, rs2004640, and rs 10954213 by selecting subjects from the GAP Registry that had been genotyped for rs2004640 and rs10954213 on the ImmunoChip (Illumina). The subjects we selected to further genotype for rs142738614 were homozygous for rs10954213. Genotyping for rs2004640 and rs10954213 was performed on the ImmunoChip by the Center for Genomics and Human Genetics at the Feinstein Institute. For rs142738614 genotyping, genomic DNA was obtained from 700 subjects homozygous for rs10954213 with membership in the GAP registry. The genotyping PCR was performed using the AmpliTaq Gold ${ }^{\circledR}$ DNA Polymerase with Buffer II and $\mathrm{MgCl}_{2}$ kit (ThermoFisher Scientific), dNTPs (Takara), DMSO (Sigma), and PCR-grade $\mathrm{H}_{2} \mathrm{O}$. Primers used for genotyping were as follows: forward 5' CTGCAGTTGCCAGGTCAGT 3', reverse 5' CGGACGCAGAGAGGAGAG 3'. Final concentrations of Taq, dNTPS, DMSO, $\mathrm{MgCl}_{2}$, primers, and DNA were $0.05 \mathrm{U} / \mu \mathrm{l}, 0.2 \mathrm{mM}, 5 \%, 1 \mathrm{mM}, 0.1 \mu \mathrm{M}$, and $0.8 \mathrm{ng} / \mu \mathrm{l}$, respectively. The touchdown PCR utilized the following cycling parameters: $95^{\circ} \mathrm{C}$ for $10 \mathrm{~min}, 12$ cycles of: $94^{\circ} \mathrm{C}$ for $30 \mathrm{~s}, 62^{\circ} \mathrm{C}$ for $30 \mathrm{~s}\left(0.5^{\circ} \mathrm{C}\right.$ decrease/cycle), $72^{\circ} \mathrm{C}$ for $1 \mathrm{~min}$, followed by 30 cycles of $94^{\circ} \mathrm{C}$ for $30 \mathrm{~s}, 56^{\circ} \mathrm{C}$ for $30 \mathrm{~s}, 72^{\circ} \mathrm{C}$ for $1 \mathrm{~min}$, followed by 1 cycle of $72^{\circ} \mathrm{C}$ for $5 \mathrm{~min}$. After the PCR, products were subjected to treatment with ExoSAP-IT ${ }^{\circledR}$ (Affymetrix) according to the manufacturer's instructions. PCR products were then sent to GENEWIZ (South Plainfield, NJ, USA) for sequencing.

\section{Human Peripheral Blood Peripheral Blood Mononuclear Cell (PBMC) and B Cell Isolation}

Up to $50 \mathrm{ml}$ of peripheral blood was drawn from consenting subjects in the GAP Registry at the Feinstein Institute for Medical Research. Blood was collected in heparinized tubes and diluted 1:1 with Hank's Balanced Salt Solution (HBSS). Diluted blood was overlaid onto Ficoll-Paque PLUS density gradient media (GE Healthcare) and centrifuged at $400 \times g$ for $30 \mathrm{~min}$ at $25^{\circ} \mathrm{C}$ with the brake and acceleration turned off. The buffy coat layer was isolated, washed with HBSS, and resuspended in staining buffer [HBSS $+2 \%$ heat inactivated fetal bovine serum (FBS) $+1 \mathrm{mM}$ EDTA]. PBMCs were counted and used for further experiments or when necessary, B cell isolation was performed with the EasySep Human B Cell Enrichment Kit (Stemcell Technologies) or the EasySep Human Naïve B Cell Enrichment Kit according to the manufacturer's instructions.

\section{Cell Lines and Primary Cell Culture}

Ramos (ATCC ${ }^{\circledR}$ CRL-1596 ${ }^{\mathrm{TM}}$ ), Raji (ATCC ${ }^{\circledR}$ CCL-86 $^{\mathrm{TM}}$ ), Daudi (ATCC $^{\circledR}$ CCL-213 $^{\mathrm{TM}}$ ), Jurkat (ATCC ${ }^{\circledast}$ TIB-152 ${ }^{\mathrm{TM}}$ ), and THP-1

${ }^{2}$ www.GAPRegistry.org (Accessed: August, 2013).
(ATCC ${ }^{\circledR}$ TIB-202 ${ }^{\mathrm{TM}}$ ) cells were obtained through the American Type Culture Collection and cultured according to ATCC recommendations in RPMI supplemented with 10\% FBS and $1 \%$ penicillin/streptomycin (ThermoFisher Scientific). Primary $\mathrm{B}$ cells and PBMCs were cultured in RPMI supplemented with $10 \% \mathrm{FBS}$ and $1 \%$ penicillin/streptomycin.

\section{Treatment of B Cells With IRF5-Activating Agents}

Primary B cells were seeded into 96-well plates in culture medium with final concentrations of $2.5 \mu \mathrm{M}$ CpG ODN 2006 (Invivogen), $5 \mu \mathrm{g} / \mathrm{ml} \mathrm{R} 848$ (Resiquimod, Invivogen), or medium alone. Cells were incubated at $37^{\circ} \mathrm{C}$ in a humidified $5 \% \mathrm{CO}_{2}$ incubator until further analysis.

\section{RNA Isolation and cDNA Synthesis}

Freshly sorted or treated B cells were pelleted and stored in Trizol at $-80^{\circ} \mathrm{C}$ until RNA isolation. RNA isolation was performed with the Direct-Zol RNA Miniprep or Microprep Kit (Zymo Research) according to the manufacturer's instructions. Freshly isolated RNA was reverse transcribed into cDNA using the iScript cDNA Synthesis Kit (BioRad) according to the manufacturer's instructions and stored at $-20^{\circ} \mathrm{C}$.

\section{Quantitative Real-Time PCR}

All TaqMan assays were obtained from ThermoFisher Scientific. In all experiments, mRNA levels were normalized to levels of the endogenous control HPRT1 (Hs99999909_m1). TaqMan assays used included IRF5 (Hs00158114_m1), FCGR2B (Hs01634996_s1), SP1 (Hs00916521_m1), and CD86 (Hs01567026_m1). For IRF5 expression in sorted B cell subsets and monocytes, cDNA was first subjected to preamplification for HPRT1 and IRF5 using the TaqMan ${ }^{\circledR}$ PreAmp Master Mix Kit (ThermoFisher Scientific) according to the manufacturer's instructions. All qPCR reactions were set up in 384-well format with master mix consisting of LightCycler 480 Probes Master (Roche), TaqMan assay, and sterile PCR-grade $\mathrm{H}_{2} \mathrm{O}$, with $1 \mu \mathrm{l}$ cDNA per reaction well $(5 \mu \mathrm{l}$ cDNA for PreAmp samples). Reactions were performed in duplicate. All TaqMan assays were done on a Roche LightCycler 480 using the following cycling parameters: one cycle of $95^{\circ} \mathrm{C}$ for $10 \mathrm{~min}$, and $45 \mathrm{cycles}$ of $95^{\circ} \mathrm{C}$ for $20 \mathrm{~s}$ followed by $60^{\circ} \mathrm{C}$ for $40 \mathrm{~s}$. Analysis of sterile transcripts was done using LightCycler 480 SYBR Green I Master (Roche), sterile PCR-grade $\mathrm{H}_{2} \mathrm{O}$, and $1 \mu \mathrm{l}$ cDNA per reaction well, in duplicate. SYBR Green assays were done on a Roche LightCycler 480 using the following cycling parameters as reported previously (34): one cycle of $95^{\circ} \mathrm{C}$ for $10 \mathrm{~min}$, and 40 cycles of $94^{\circ} \mathrm{C}$ for $1 \mathrm{~min}, 58^{\circ} \mathrm{C}$ for $1 \mathrm{~min}$, and $72^{\circ} \mathrm{C}$ for $1 \mathrm{~min}$. A melting curve analysis was also performed with continuous acquisition starting at $97^{\circ} \mathrm{C}$ and ending at $40^{\circ} \mathrm{C}$. Primer sets for sterile transcripts included HPRT1: forward 5' TGCAGACTTTGCTTTCCTTGGTCAGG 3, reverse 5' CCAACACTTCGTGGGGTCCTTTTCA 3', and germline IgG: forward 5' TCCTCTCAGCCAGGACCAA 3, reverse 5' TCTTGGCATTATGCACCTCC 3' (34). The final concentration of primers used was $0.1 \mu \mathrm{M}$. For baseline expression experiments, relative mRNA expression levels were calculated using the $\Delta \mathrm{Ct}$ 
method, $2^{\text {(Ct endogenous control - Ct gene of interest) }}$. For experiments involving treatment of B cells with IRF5 activating agents, relative mRNA expression levels were calculated using the $\Delta \Delta \mathrm{Ct}$ method,

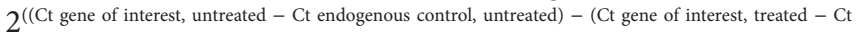
endogenous control, treated)).

\section{Fluorescence-Activated Cell Sorting}

For B cell subset sorting, cryopreserved PBMCs were thawed and stained with the following monoclonal antibodies for $30 \mathrm{~min}$ on ice in the dark: $\alpha$ IgD-FITC, $\alpha$ CD27-PE, $\alpha$ CD38-PE-Texas Red (BD Biosciences), $\alpha \mathrm{CD} 10-\mathrm{PE}-\mathrm{Cy} 7, \alpha \mathrm{CD} 19-\mathrm{APC}$ (BioLegend), and $\alpha \mathrm{CD} 14$-Pacific Blue (BD Biosciences). For sorting of transfected Raji and Daudi B cells, cells were transfected with either empty or IRF5 overexpressing vectors with a cyan fluorescent protein (CFP) overexpressing reporter vector (see Transient Transfection and IRF5 Overexpression), and $24 \mathrm{~h}$ later prepared for sorting by pelleting and resuspended in staining buffer. Immediately before sorting, $1 \mu$ l propidium iodide (PI) (ThermoFisher Scientific) was added to the cells. PI negative, CFP-positive cells were sorted, pelleted, and stored in Trizol at $-80^{\circ} \mathrm{C}$. In all experiments, cells were sorted using a BD FACSAria or BD FACSAria SORP.

\section{Flow Cytometry}

The monoclonal antibody 2B6 that was used for Fc $\gamma$ RIIb staining has been described previously (35). All cell surface staining conditions took place in staining buffer for $30 \mathrm{~min}$ on ice in the dark. For baseline Fc $\gamma$ RIIb expression in B cell subsets, cryopreserved PBMCs from genotyped GAP subjects were thawed and incubated with the following monoclonal antibody cocktail: $\alpha$ Fc $\gamma$ RIIb-AF488 (Macrogenics), $\alpha I g D-P E, ~ \alpha C D 27-A P C$, $\alpha C D 19-P e r C P, \alpha C D 38-A P C-C y 7, \alpha C D 10-P E-C y 7$ (BioLegend), $\alpha \mathrm{CD} 14$-Pacific Blue (BD Biosciences), and as a dump gate $\alpha \mathrm{CD} 3$ and $\alpha \mathrm{CD} 16$, both AF700 conjugated. The fixable viability dye eFluor506 was included for live/dead discrimination (eBioscience). For analysis of stimulated primary B cells, cells were incubated with eFluor660 fixable viability dye, $\alpha$ CD19-BV421 (BioLegend) and $\alpha$ Fc $\gamma$ RIIb-AF488. For measurement of Fc $\gamma$ RIIb in IRF5 overexpression experiments, cells were incubated with the fixable viability dye eFluor660 and $\alpha$ Fc $\gamma$ RIIb-AF488. Only $\mathrm{CFP}^{+}$cells were considered in the analysis. For analysis of antibody-secreting cultured B cells, on the fourth day of culture $B$ cells were stained with $\alpha$ CD19-APC-Cy7, $\alpha$ CD27-PE, $\alpha$ CD38PE-Texas Red, $\alpha$ CD86-BV711 (BioLegend), $\alpha$ CD138-BV421 (BioLegend), $\alpha$ IgM-PerCP-Cy5.5 (BioLegend), and $\alpha$ IgG-PeCy7 (BD Biosciences), and viability dye eFluor506. All experimental data were acquired on a BD LSRII or LSR Fortessa and analyzed using FlowJo software (Treestar).

\section{Apoptosis Assay}

Peripheral blood mononuclear cells or were cultured medium with either vehicle (DMSO) or CPT-11 (Sigma) at concentrations of $50 \mu \mathrm{M}$. Cells were incubated for $8 \mathrm{~h}$ in a $37^{\circ} \mathrm{C}$ humidified $5 \% \mathrm{CO}_{2}$ incubator. After incubation, cells were stained with eFluor506 viability dye, $\alpha$ CD19-APC (BioLegend), and $\alpha$ CD14Pacific Blue. Cells were then prepared for analysis using the PE anti-active caspase 3 apoptosis kit (BD Biosciences) according to the manufacturer's instructions. Cells were analyzed on a BD LSR Fortessa.

\section{ELISpot Assay}

On the fourth day of primary B cell culture, Immunolon ${ }^{\circledR}$ flatbottom 96-well microtiter plates (ThermoFisher Scientific) were coated with goat antihuman IgM (Southern Biotech) at a final concentration of $10 \mu \mathrm{g} / \mathrm{ml}$ in HBSS for $1 \mathrm{~h}$ at $37^{\circ} \mathrm{C}$. Plates were then washed and blocked with culture medium for $1 \mathrm{~h}$ at room temperature. Live cells were counted via trypan blue exclusion and seeded as serial 1:2 dilutions in fresh culture medium in the plate in duplicate. Plates were briefly spun to settle cells to the bottom and incubated overnight in a $37^{\circ} \mathrm{C}$ humidified $5 \% \mathrm{CO}_{2}$ incubator. Plates were subsequently washed and biotinylated goat antihuman IgM was added at a final concentration of $1.6 \mu \mathrm{g} / \mathrm{ml}$. The plates were incubated for $2 \mathrm{~h}$ at $37^{\circ} \mathrm{C}$. Plates were washed again and alkaline phosphatase (AP)-conjugated streptavidin was added at a dilution of $1: 1,000$ and incubated for $1 \mathrm{~h}$ at $37^{\circ} \mathrm{C}$. Plates were washed and developing solution was added: $1 \mathrm{mg} / \mathrm{ml} \mathrm{BCIP}$ (Sigma) in AMP buffer. Color development took place at room temperature in the dark until spots appeared; plates were then rinsed with $\mathrm{dH}_{2} \mathrm{O}$, dried and counted under a light microscope.

\section{ELISA}

The protocol followed for the ELISA was the same as the ELISpot assay with a few modifications. Costar ${ }^{\circledR}$ 96-well flat-bottom plates were used (Corning) and blocking was done with 3\% FBS. IgM standards and sample supernatants were also diluted in $3 \%$ FBS and incubated for $1.5 \mathrm{~h}$. The incubation with the secondary antibody, AP-goat anti human IgM (Southern Biotech) was done at a dilution of 1:1,000 and lasted for $1 \mathrm{~h}$. The developing solution consisted of $0.05 \mathrm{M} \mathrm{Na}_{2} \mathrm{CO}_{3}, 0.001 \mathrm{M} \mathrm{MgCl}_{2}$, and phosphatase substrate (Sigma). Absorbance was measured at $405 \mathrm{~nm}$.

\section{Generation of IRF5- and CPF-Overexpressing Constructs}

We obtained a plasmid expressing both IRF5 (NM_001098629.1) and CFP (GenBank: KT878729.1) as a fusion protein (Genecopoeia). Both the IRF5 and CFP ORFs were cloned into the pmaxCloning ${ }^{\mathrm{TM}}$ vector (Lonza) separately. For the cloning of CFP, a PCR was done on the donor fusion protein plasmid to introduce HindIII and XhoI sites for more straightforward cloning. The PCR primers used were as follows: forward $5^{\prime}$ GATAAGCTTTCTTGTACA-AAGTGGTTCG 3', reverse 5' CACACTCGAGGTAAAAGGACAGG 3'. The PCR consisted of 50 ng plasmid DNA, reaction buffer, pfuUltra High-Fidelity DNA polymerase, dNTP mix, $0.1 \mu \mathrm{M}$ primers, and PCR-grade $\mathrm{H}_{2} \mathrm{O}$. The reaction buffer, polymerase, and dNTP mix were taken from the QuikChange II Site-Directed Mutagensis Kit (Agilent Technologies). Cycling parameters were as follows: $95^{\circ} \mathrm{C} 30 \mathrm{~s}, 25$ cycles of $95^{\circ} \mathrm{C}$ for $30 \mathrm{~s}, 55^{\circ} \mathrm{C}$ for $1 \mathrm{~min}$, and $68^{\circ} \mathrm{C}$ for $1 \mathrm{~min}$, followed by one cycle of $72^{\circ} \mathrm{C}$ for $5 \mathrm{~min}$. The product was purified and restriction digested with XhoI and HindIII. The pmaxCloning ${ }^{\mathrm{TM}}$ vector was also digested with XhoI and HindIII and dephosphorylated with Antarctic AP (New England Biolabs). Products were purified and ligated 
with T4 DNA ligase (New England Biolabs). DH5 $\alpha-\mathrm{TI}^{\mathrm{R}}$ E. coli (ThermoFisher Scientific) were transformed and subject to kanamycin resistance selection. Resistant colonies were picked and screened via colony PCR using the same primers and cycling conditions of: $95^{\circ} \mathrm{C}$ for $10 \mathrm{~min}, 30$ cycles of $95^{\circ} \mathrm{C}$ for $20 \mathrm{~s}, 56^{\circ} \mathrm{C}$ for $30 \mathrm{~s}, 72^{\circ} \mathrm{C}$ for $1 \mathrm{~min}$, and one cycle of $72^{\circ} \mathrm{C}$ for $5 \mathrm{~min}$. The PCR mix consisted of the same reagents at the same concentrations as indicated in Section "Genotyping." PCR products were visualized on a $1 \%$ agarose gel with SYBR Safe DNA Gel Stain (ThermoFisher Scientific). A positive colony was further grown in E. coli and plasmid was isolated using the ZymoPURETM Plasmid Maxiprep Kit (Zymo Research). Confirmation of plasmid sequence was done at Genewiz (South Plainfield, NJ, USA) with the forward and reverse primers. For the cloning of IRF5, a PCR was also done on the donor fusion protein plasmid to introduce EcoRI and XhoI sites for more straightforward cloning. The primers used were as follows: forward $5^{\prime}$ TATAGAATTCCCAAG-CTGGCTAGTTAAG 3', reverse $5^{\prime}$ TATACTCGAGATCGAACCACTTTGTACAAGAAA 3'. The PCR consisted of 150 ng plasmid DNA, PrimeSTAR ${ }^{\circledR}$ HS DNA Polymerase with reaction buffer (Takara), $0.25 \mu \mathrm{M}$ primers, $0.2 \mathrm{mM}$ dNTPS (Takara), and sterile PCR-grade $\mathrm{H}_{2} \mathrm{O}$. Cycling conditions were $30 \mathrm{cycles}$ of $98^{\circ} \mathrm{C}$ for $10 \mathrm{~s}, 55^{\circ} \mathrm{C}$ for $15 \mathrm{~s}$, and $72^{\circ} \mathrm{C}$ for $1 \mathrm{~min}$. The product was purified and restriction digested with XhoI and EcoRI. The pmaxCloning ${ }^{\mathrm{TM}}$ vector was also digested with XhoI and EcoRI. Recipient vector dephosphorylation, ligation, and transformation, and colony PCR procedures were the same as done for CFP, but colony PCR primers were as follows: forward 5' CCTGTGTCAGTGCAAGGTGT 3', reverse 5' TTCCCCAAAGCAGA-AGAAGA 3'. Products were also visualized on a $1 \%$ agarose gel. A positive colony was grown up and plasmid DNA isolated the same way as for CFP. Confirmation of plasmid sequence was done at GENEWIZ (South Plainfield, NJ, USA) with the forward and reverse primers.

\section{Generation of Luciferase Reporter Constructs}

We obtained another plasmid with the non-risk IRF5 promoter (NM_002200) from Genecopoeia (HPRM19470-PG02). To obtain the promoter with the risk allele, a PCR was performed on donor genomic DNA with restriction sites for EcoRI and HindIII in the product. The primers used were as follows: forward $5^{\prime}$ TCTTGGAATTCCCCTCCTGTTTTCCTTCCCTGCTAT 3', reverse 5' GCCA-ACCTGCCGGGCACT 3'. The reaction used 20 ng DNA and the same reagents and concentrations as the PCR described in Section "Genotyping," but final concentrations of DMSO, $\mathrm{MgCl}_{2}$, and primers were $3.5 \%, 1.5 \mathrm{mM}$, and $0.5 \mu \mathrm{M}$, respectively. The cycling conditions were $95^{\circ} \mathrm{C}$ for $5 \mathrm{~min}, 38$ cycles of $95^{\circ} \mathrm{C}$ for $20 \mathrm{~s}, 63^{\circ} \mathrm{C}$ for $30 \mathrm{~s}, 72^{\circ} \mathrm{C}$ for $1 \mathrm{~min}$, and $1 \mathrm{cycle}$ of $72^{\circ} \mathrm{C}$ for $5 \mathrm{~min}$. Both the donor plasmid and PCR product were restriction digested with EcoRI and HindIII; the donor plasmid was then dephosphorylated, ligated with the product, transformed into E. coli, grown and isolated the same way as described in "Generation of IRF5 and CPF-overexpressing constructs." At this point we had two plasmids; one with the non-risk allele and one with the risk allele. We also obtained pGL4.10 promoterless Firefly and pRL thymidine kinase (TK) promoter-driven Renilla luciferase vectors (Promega). We digested the promoterless firefly vector, the non-risk allele plasmid, and the risk allele plasmid with BglII and HindIII (New England Biolabs), dephosphorylated the donor Firefly vector, and ligated it with either the purified non-risk or risk allele insert. Ligation products were transformed into E. coli and selected based on carbenicillin resistance. Colonies were picked and screened via colony PCR using the same primers as in Section "Genotyping." The colony PCR was done with the same reagents and concentrations as in Section "Genotyping," but cycling conditions were as follows: $95^{\circ} \mathrm{C}$ for $10 \mathrm{~min}, 40$ cycles of $95^{\circ} \mathrm{C}$ for $20 \mathrm{~s}, 56^{\circ} \mathrm{C}$ for $30 \mathrm{~s}, 72^{\circ} \mathrm{C}$ for $1 \mathrm{~min}$, and $1 \mathrm{cycle}$ of $72^{\circ} \mathrm{C}$ for $5 \mathrm{~min}$. Products were visualized on a $1 \%$ agarose gel. A successful colony was transformed into E. coli, grown and isolated the same way as described in "Generation of IRF5 and CPF-overexpressing constructs." The resulting non-risk allele Firefly vector and risk allele Firefly vector were confirmed by sequencing at GENEWIZ with the forward primer used in Section "Genotyping." Mutation of the risk allele in the Firefly vector to a non-SP1 binding site was done with the QuikChange II Site-Directed Mutagensis Kit according to manufacturer's instructions. The mutagenic primers used were as follows: forward 5' GGGCGGGGCGGTTCCGGGCAC-TGCCC 3', reverse 5' GGGCAGTGCCCGGAACCGCCCCGCCC 3'.

\section{Transient Transfection and IRF5 Overexpression}

Raji and Daudi cells were transfected with $4 \mu \mathrm{g}$ plasmid DNA using the Amaxa Nucleofector Kit V and $3 \mu \mathrm{g}$ DNA using the Amaxa Nucleofector ${ }^{\mathrm{TM}}$ Kit L (Lonza), respectively, according to the manufacturer's instructions. Half the amount of DNA in each cotransfection reaction consisted of the CFP reporter vector, and the resultant amount consisted of either IRF5 overexpression vector or empty vector. To control for plasmid size, IRF5 overexpression vector or empty vector were transfected in equimolar amounts. Transfected cells were incubated in culture medium for $24 \mathrm{~h}$ at $37^{\circ} \mathrm{C}$ in a humidified $5 \% \mathrm{CO}_{2}$ incubator. For experiments involving stimulation of transfected cells with IRF5 activating agents, cells were placed into culture medium with $2.5 \mu \mathrm{M} \mathrm{CpG}$ or $5 \mu \mathrm{g} / \mathrm{ml} \mathrm{R} 848$ immediately after transfection.

\section{Luciferase Reporter Gene Assay}

The following table illustrates transfection conditions for the given cell lines:

\begin{tabular}{lcccc}
\hline Cell line & $\boldsymbol{\mu g}$ DNA & $\begin{array}{c}\text { Nucleofector } \\
\text { Line Kit and program }\end{array}$ & $\begin{array}{c}\text { Ratio } \\
\text { firefly:renilla }\end{array}$ & $\begin{array}{c}\text { Incubation } \\
\text { time (h) }\end{array}$ \\
\hline Ramos & 4 & V, O-06 & $10: 1$ & 16 \\
Raji & 4 & V, M-13 & $10: 1$ & 16 \\
Daudi & 3 & L, A-20 & $10: 1$ & 16 \\
Jurkat & 2 & V, X-01 & $10: 1$ & 16 \\
THP-1 & 2 & V, V-01 & $2: 1$ & 13 \\
\hline
\end{tabular}

Transfected cells were incubated in culture medium for $24 \mathrm{~h}$ at $37^{\circ} \mathrm{C}$ in a humidified $5 \% \mathrm{CO}_{2}$ incubator. After incubation, firefly and renilla activity was measured using the Dual-Glo ${ }^{\circledR}$ Luciferase Assay System (Promega) according to the manufacturer's instructions. Four independent experiments were done with all 
five cell lines comparing the risk and non-risk promoters; three independent experiments were done with THP-1 cells comparing the risk, non-risk, and mutated promoters.

\section{Electro-Mobility Shift and Supershift Assays}

Ramos, Raji, Daudi, and THP-1 cells were subcultured at $4 \times 10^{5} /$ $\mathrm{ml}$ and harvested when a total of $35 \times 10^{6}$ cells was present $(\sim 48 \mathrm{~h}$ later). Nuclear extract was prepared using the NE-PER ${ }^{\circledR}$ Nuclear and Cytoplasmic Extraction Kit (ThermoFisher Scientific) according to the manufacturer's instructions. Infrared $(700 \mathrm{~nm})$ labeled oligonucleotides were obtained from Integrated DNA Technologies (Coralville, IA, USA). Probe sequences used were as follows: non-risk 5' AGTGGATTCGCGGGG-CGGGGCGGG GCACTGC3', risk5' AGTGGATTCGCGGGGCGGGGCGGGGC GGGGCACT-GC 3'. The Odyssey Infrared electro-mobility shift assay (EMSA) Kit (LI-COR) was used according to the manufacturer's instructions. For supershift reactions, $1 \mu \mathrm{g}$ rabbit anti-SP1 or isotype control (Cell Signaling Technology) was used. Gels were imaged on a LI-COR Infrared Odyssey machine.

\section{Statistical Analysis}

Statistical analyses were performed with GraphPad Prism 6 software. Statistical significance was determined with the following tests where indicated: Friedman test with Dunn's multiple comparison test, Wilcoxon matched-pairs signed rank test, Mann-Whitney test, and the Kruskal-Wallis test. $p$ Values $<0.05$ were considered significant.

\section{RESULTS}

\section{Common IRF5 Risk and Non-Risk Haplotypes Are Present Across Various Populations}

Using the 1000 Genomes Project data (36), we determined haplotype frequencies for the IRF5 locus (Figure 1A) for AFRs, Latino/ Hispanics, EASs, EURs, and SASs Most of the IRF5 variants associated with SLE are in a high degree of LD (Figure 1B). In all populations, the risk variants of rs142738614, rs2004640, rs10954213, and rs10488631 are inherited together, with the exception of the risk allele of rs10488631 which is present at a frequency $<5 \%$ in AFRs and EASs. Our data show that (1) rs142738614, rs2004640, and rs10954213 are three suitable markers for determining the presence of the common risk and non-risk haplotype across populations and (2) four copies of the CGGGG sequence of the rs142738614 promoter indel is a suitable proxy for the risk haplotype.

\section{IRF5 Expression Is Higher in Monocytes and IgD- Memory B Cell Subsets Independent of Haplotype}

In SLE, B cell tolerance checkpoints are compromised (37), and it has been shown that SLE risk alleles can affect those tolerance checkpoints. To address whether the IRF5 risk haplotype might affect B cell tolerance, we first asked whether IRF5 expression differs across B cell subsets and whether the risk and non-risk haplotypes are differentially regulated as expression quantitative

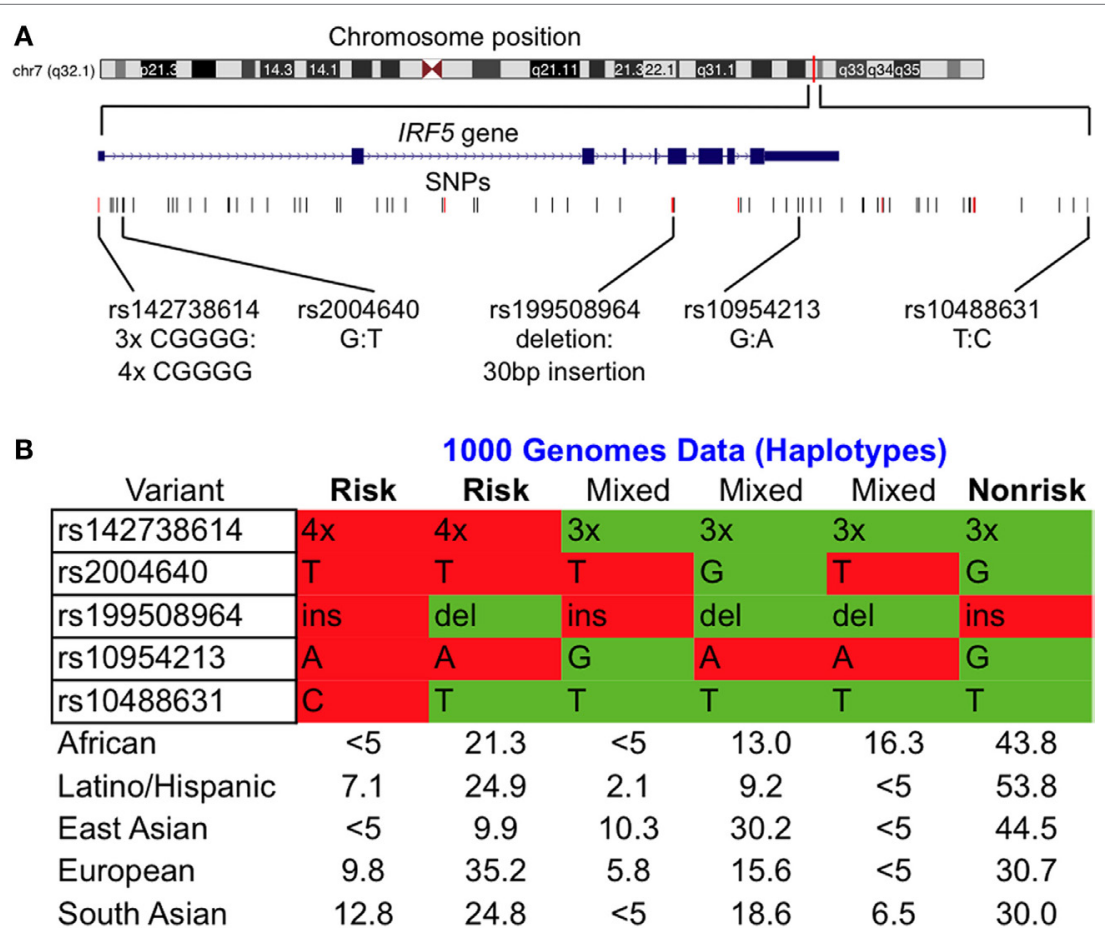

FIGURE 1 | Common interferon regulatory factor 5 (IRF5) risk and non-risk haplotypes are present across various populations. (A) Chromosomal location of the IRF5 locus of interest with SNPs considered in our study. Alleles are indicated as non-risk:risk. (B) Condensed haplotypes obtained from 1000 Genomes present in $>5 \%$ of the indicated ethnic populations. Those labeled risk and non-risk were included in our study. Abbreviations: ins, insertion; del, deletion. 
trait loci (eQTL). We compared expression of IRF5 in B cells alongside expression of IRF5 in monocytes. We sorted monocytes based on expression of CD14 and gated B cells based on CD19 expression. CD19 ${ }^{+} \mathrm{B}$ cells were sorted into four populations: naïve $\left(\mathrm{IgD}^{+} \mathrm{CD} 27^{-} \mathrm{CD} 10^{\text {lo }} \mathrm{CD} 38^{\text {lo }}\right)$, transitional $\left(\mathrm{IgD}^{+} \mathrm{CD} 27^{-} \mathrm{CD} 10^{\mathrm{hi}} \mathrm{CD} 38^{\mathrm{hi}}\right)$, and $\mathrm{CD} 27^{+}$memory B cells, both $\mathrm{IgD}^{+} \mathrm{CD} 27^{+}$and $\mathrm{IgD}^{-} \mathrm{CD} 27^{+}$(Figure 2A). IRF5 expression was significantly higher in monocytes than in $\mathrm{B}$ cells, and highest in $\mathrm{CD}^{2} 7^{+} \operatorname{IgD}{ }^{-} \mathrm{B}$ cells out of all the sorted B cell subsets (Figure $2 \mathrm{~B}$ ). Whether or not B cells or monocytes were from subjects carrying the risk or non-risk haplotype did not affect gene expression (Figure 2C). Thus, although IRF5 may play an important role in class switched, antigen-experienced B cells, the presence of the IRF5 risk haplotype does not alter gene expression in unstimulated, circulating B cells or unstimulated monocytes.

\section{IRF5 Risk Alleles Do Not Differentially Affect IRF5 Expression by In Vitro \\ Stimulated B Cells}

The impact of some disease-associated risk haplotypes is seen only in activated cells as "response eQTLs." We therefore asked whether stimulation of $\mathrm{B}$ cells through an IRF-dependent pathway would trigger haplotype-specific expression differences. B cells were stimulated with the TLR9 and TLR7 agonists, CpG or R848, respectively, for 5 or $24 \mathrm{~h}$ and IRF5 gene expression was measured. Successful B cell stimulation was confirmed by increased CD86 expression after $5 \mathrm{~h}$ (Figure 3A). We observed a slight but significant increase in IRF5 expression $5 \mathrm{~h}$ after $\mathrm{CpG}$ stimulation as well as a decrease in expression $24 \mathrm{~h}$ after $\mathrm{CpG}$ or R848 stimulation (Figure 3B) confirming that IRF5 is within the TLR7 and 9 pathways. The presence of the IRF5 risk or nonrisk haplotype did not differentially affect the response to TLR agonists (Figure 3C).

\section{Susceptibility to Apoptosis in B Cells Does Not Differ According to IRF5 Haplotype}

While we observed no significant difference in basal or stimulated levels of expression of IRF5, we thought it important to ask whether an effect of the IRF5 risk haplotype might be revealed in a more sensitive bioassay. IRF5 is known to play a critical role in cell cycle arrest and cell death (7). Irinotecan (CPT-11), a potent topoisomerase inhibitor and DNA damaging agent, activates an

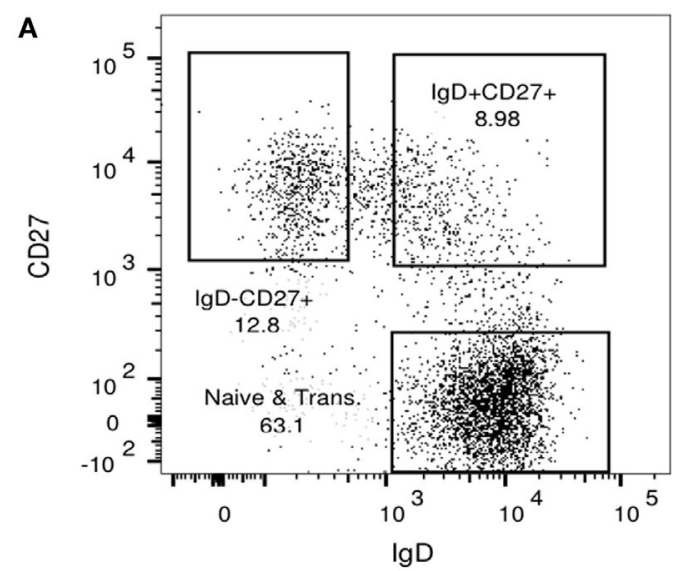

B

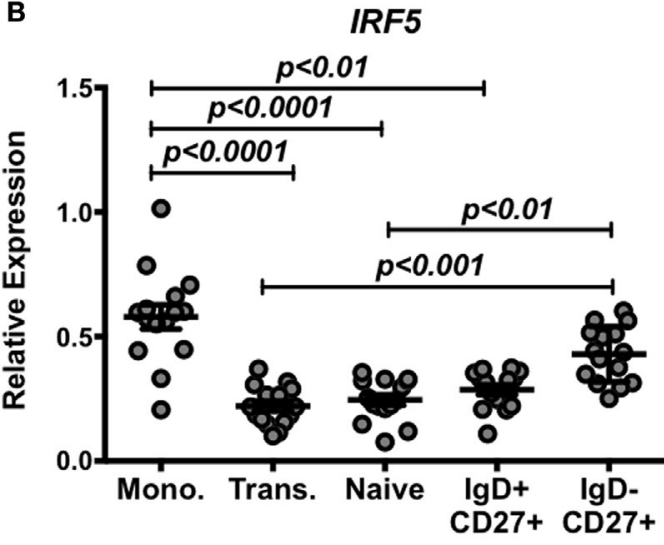

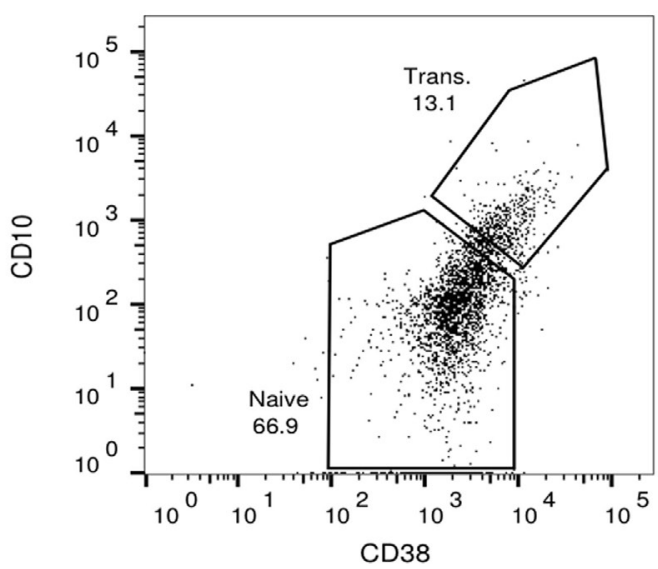

C

IRF5

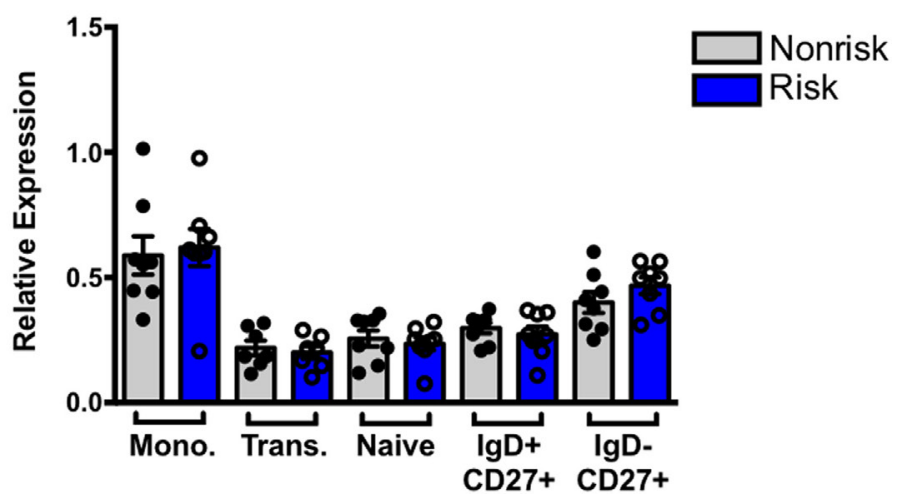

FIGURE 2 | Interferon regulatory factor 5 (IRF5) expression is higher in monocytes and IgD- memory B cell subsets independent of haplotype. Monocytes and four subsets of $\mathrm{B}$ cells were sorted after gating on $\mathrm{CD} 14^{+}$and $\mathrm{CD} 19^{+}$cells, respectively. (A) Gating strategy for lgD ${ }^{+} \mathrm{CD} 27^{+}, \operatorname{lgD}{ }^{-} \mathrm{CD} 27^{+}, \mathrm{CD}^{2} 7^{-} \mathrm{CD} 10^{\circ} \mathrm{CD} 38^{10}($ naive), and CD27-CD10 hi CD38 ${ }^{\text {hi }}$ (transitional) B cells. Sorted cells were subjected to qPCR for IRF5 (B,C), and results are shown combined (B) and separated by haplotype (C). $p<0.01$ by Friedman test with Dunn's multiple comparisons test (B), $p=$ ns by Mann-Whitney test for each B cell subset (C). 
A

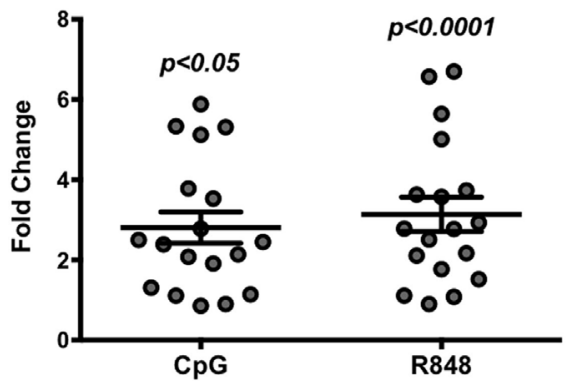

C

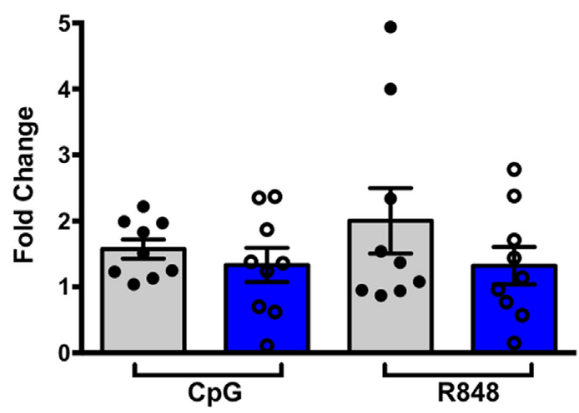

B

IRF5

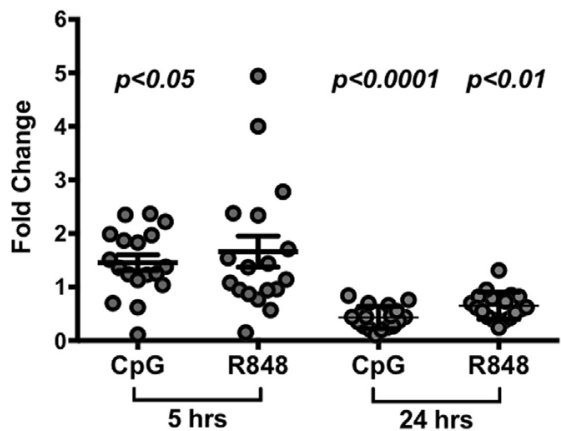

IRF5: 24hrs

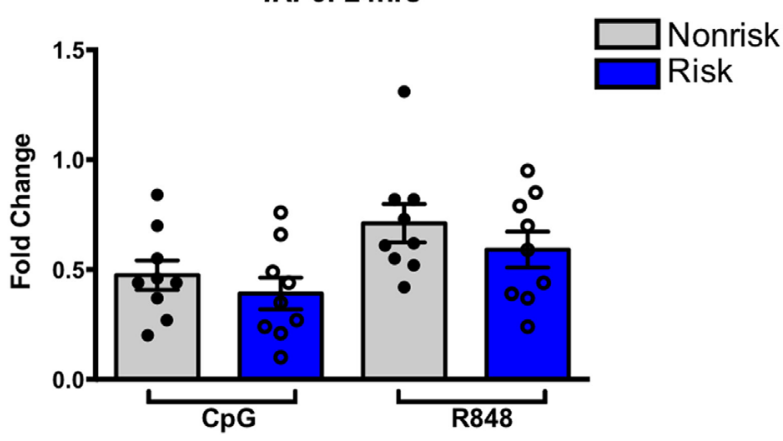

FIGURE 3 | Interferon regulatory factor 5 (IRF5) risk alleles do not affect induced IRF5 expression in B cells. Purified B cells were stimulated with toll-like receptor agonists CpG or R848 for the indicated times and subjected to qPCR for CD86 (A) or IRF5 (B,C) IRF5 qPCR. Results are shown combined (B) and separated by haplotype (C). Unstimulated cell expression values are normalized to 1.0. $p<0.05, p<0.01$, and $p<0.0001$ by Friedman test with Dunn's multiple comparisons test (A,B), $p=$ ns by Wilcoxon matched-pairs signed rank test for each treatment (C).

IRF5-dependent apoptotic program (38). We asked whether IRF5 haplotypes differentially affect apoptosis induced by CPT-11. PBMCs from healthy genotyped donors were treated with $50 \mu \mathrm{M}$ CPT-11 or vehicle for $8 \mathrm{~h}$ and analyzed for the expression of active caspase 3 by flow cytometry. CPT-11 induced a significant increase in caspase 3 positive PBMCs (Figure 4A). The effect of CPT-11 on inducing active caspase 3 was evident in both $\mathrm{B}$ cells $\left(\mathrm{CD} 19^{+}\right)$and monocytes $\left(\mathrm{CD} 14^{+}\right.$) (Figures 4C,D, top). Interestingly, there was a haplotype dependent induction of apoptosis in monocytes; risk haplotype carriers had a higher proportion of cells undergoing apoptosis than non-risk haplotype carriers (Figures 4B,D, bottom). This haplotype dependent induction of apoptosis was not evident in B cells (Figures 4B,C, bottom). These findings suggest that although IRF5 plays a role in apoptosis in multiple cell types, the SLE risk haplotype enhances IRF5-mediated apoptosis in monocytes and not in B cells.

\section{IRF-Specific B Cell Stimulation Results in Upregulated CD86 Expression and ASC Differentiation}

Based on murine studies, IRF5 has been shown to play a role in heavy chain class switch recombination to $\operatorname{IgG}(17,18)$ and in plasma cell differentiation which requires upregulation of the transcription factor Blimp1 (15); IRF5 controls Blimp1 expression.
We were interested in determining whether IRF5 haplotypes differentially promote class switching and plasma cell differentiation in human B cells. Naïve B cells were cultured with or without CpG for 4 days and subjected to multiple functional assays including ELISpot, ELISA, and flow cytometry. B cell activation was demonstrated by upregulation of CD86 (Figures 5A,B, left), but the degree of upregulation did not differ according to haplotype (Figure 5B, right). ELISpot analysis indicated that $\mathrm{CpG}$ induced B cells to differentiate into IgM ASCs (Figure 5C, far left). We confirmed IgM secretion by ELISA (Figure 5C, center right). CpG treated cells also exhibited increased surface IgM (Figure 5D, left and center). In all these analyses, results did not differ according to IRF5 haplotype (Figure 5C, center left and far right; Figure 5D, right).

IgG secreting cells or surface $\mathrm{IgG}^{+}$cells were not detected after the 4-day culture (data not shown), suggesting CpG alone may not be sufficient to induce class switching to IgG or that 4-day cultures are too short term for production of IgG to be evident. We therefore decided to perform quantitative PCR to measure the relative abundance of IgG germline mRNA in naïve $B$ cells cultured with or without $\mathrm{CpG}$ for $24 \mathrm{~h}$. Transcription of germline constant region mRNA is reported to precede isotype switching (39); the resulting transcripts are not translated into protein and are therefore termed "sterile transcripts." We considered that we might detect these sterile transcripts before we could detect 


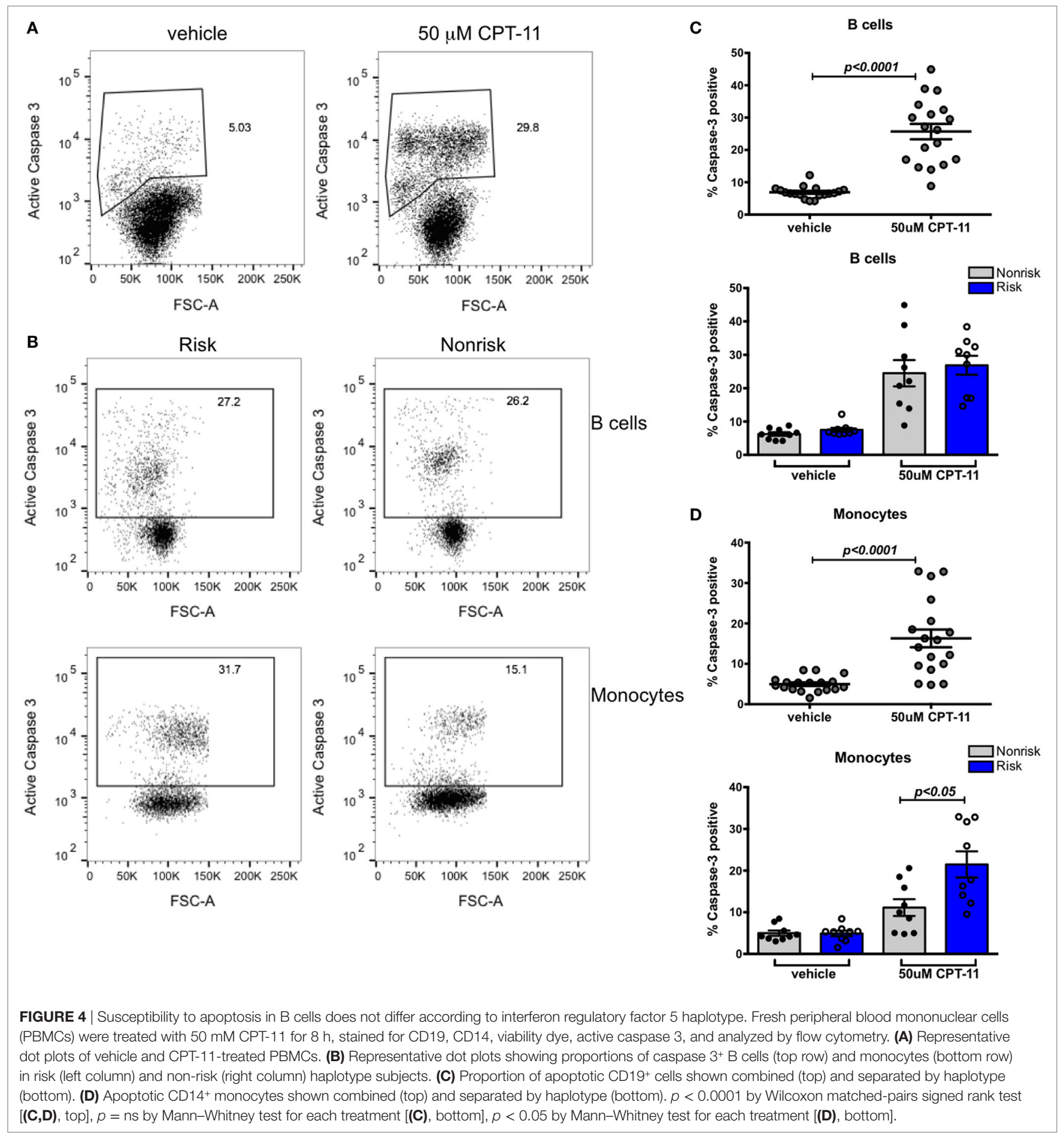

IgG proteins. Surprisingly, we observed a decrease in abundance of sterile transcripts (Figure 6) and this decrease was observed equally in risk and non-risk haplotype B cells, suggesting that TLR7 and 9 signaling may not be sufficient for class switch recombination. Overall, we found that $\mathrm{CpG}$ stimulation upregulates CD86 and surface IgM on B cells and transforms naïve B cells into IgM secreting cells, and these effects occur independent of IRF5 haplotype.

\section{IRF5 Does Not Affect Fc $\gamma$ RIlb Expression in B Cells}

The expression of FcyRIIb on B cells represents an important $B$ cell tolerance mechanism. Triggering FcyRIIb serves as one mechanism to limit B cell activation through delivery of inhibitory signals that contribute to regulation of the immune response (22). SLE patients fail to upregulate Fc $\gamma$ RIIb on $\mathrm{CD} 27^{+}$memory B cells (40). Studies with mouse models suggest the existence of 

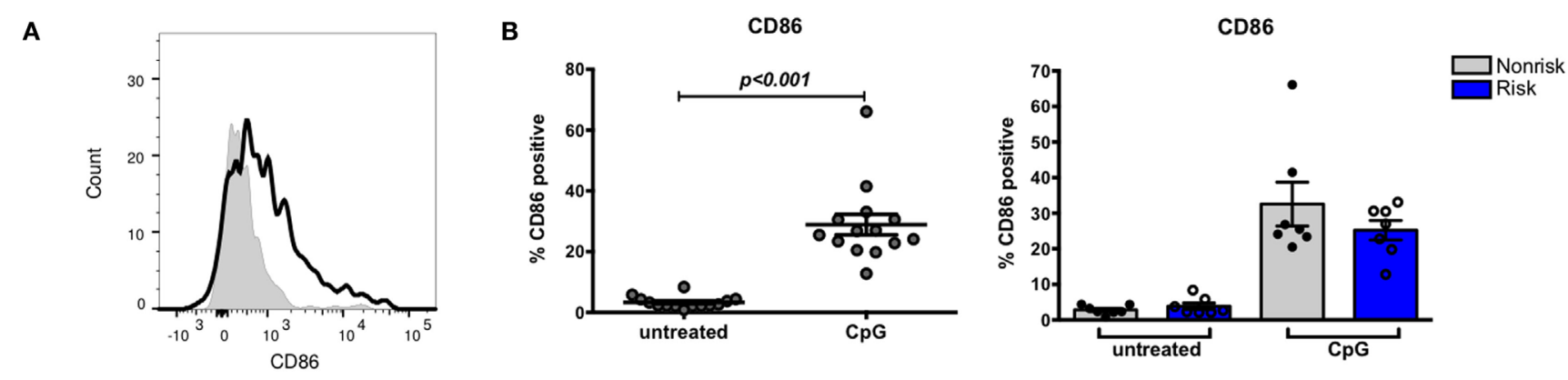

C
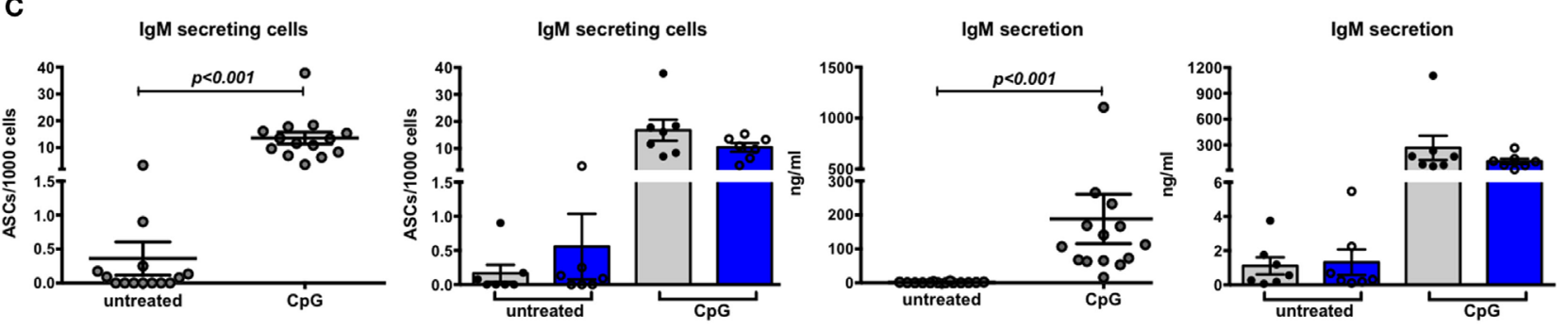

D
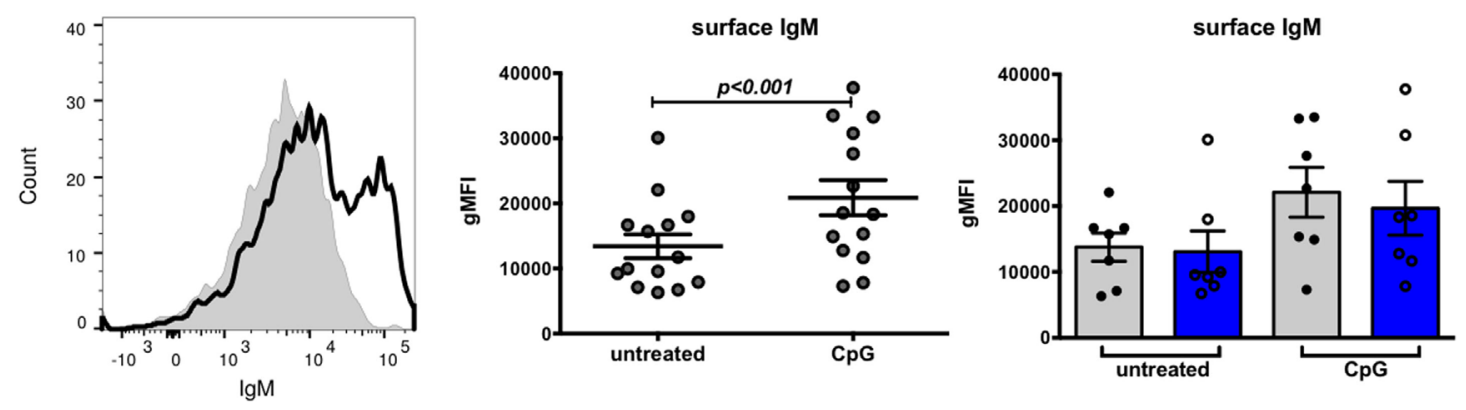

FIGURE 5 | B cell stimulation results in upregulated CD86 expression and antibody-secreting cell (ASC) differentiation. Naive B cells were cultured for 4 days with or without $\mathrm{CpG}$ and analyzed by flow cytometry. (A) Representative histogram of CD86 expression on untreated (shaded peak) and CpG-treated (black outlined peak) B cells. (B) CD86 expression on B cells combined (left) and separated by haplotype (right). (C) ELISpot data showing proportion of ASCs combined (far left) and separated by haplotype (center left) and ELISA data showing IgM secretion by B cells combined (center right) and separated by haplotype (far right).

(D) Representative histogram of surface IgM expressed on untreated (shaded peak) and CpG-treated (black outlined peak) B cells. Flow cytometric results of IgM expression on B cells combined (center) and separated by haplotype (right). $p<0.001$ by Wilcoxon matched-pairs signed rank test [(B), left; (C), far left and center right; (D), center], $p=$ ns by Mann-Whitney test for each treatment [(B), right; (C), center left and far right; (D), right].
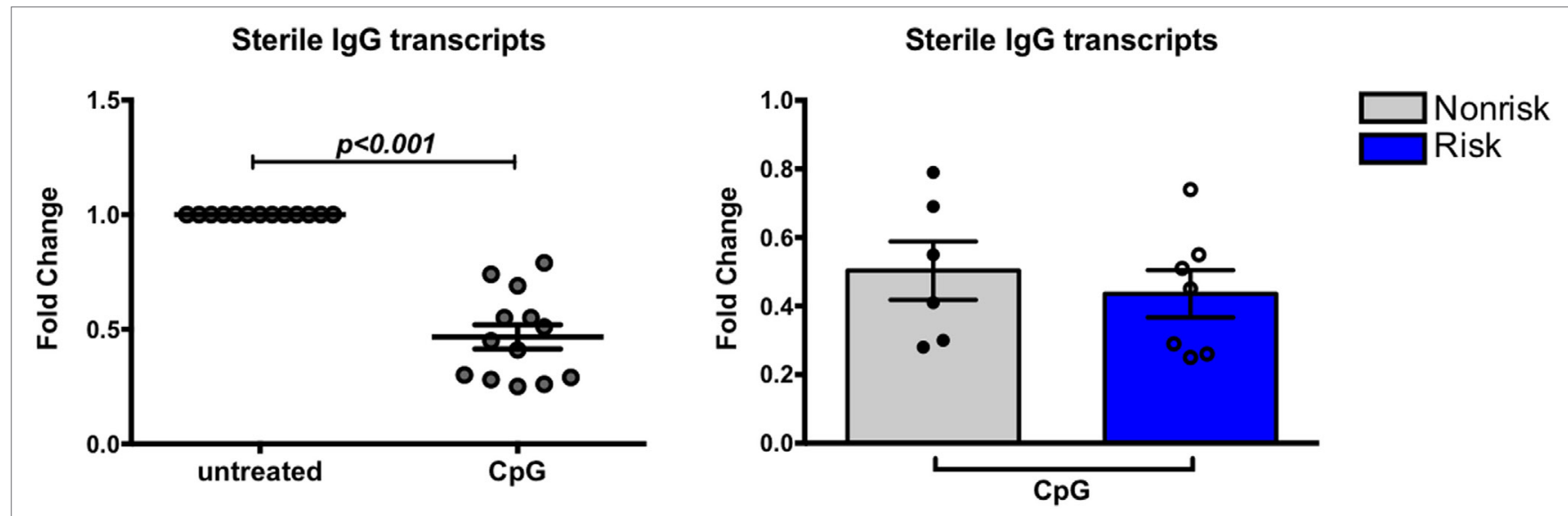

FIGURE 6 | Expression of sterile transcripts in B cells. B cells were cultured for $24 \mathrm{~h}$ with or without CpG and subject to qPCR for germline IgG. Results are shown combined (left) and separated by haplotype (right). $p<0.001$ (left) by Wilcoxon matched-pairs signed rank test, $p=\mathrm{ns}$ by Mann-Whitney test (right). 
crosstalk between FcyRIIb and IRF5 with negative regulation of FcyRllb by IRF5 (20). We asked whether a relationship between IRF5 and Fc $\gamma$ RIIb exists in human B cells, and if the IRF5 risk haplotype might be associated with a decrease in Fc $\gamma$ Rllb expression. Expression of FcyRIIb was measured on B cell subsets from genotyped subjects using flow cytometry. Overall, Fc $\gamma$ RIIb expression was highest on $\mathrm{IgD}^{+} \mathrm{CD} 27^{+} \mathrm{B}$ cells (Figure 7A). IRF5 haplotype did not differentially affect Fc $\gamma$ RIIb expression in any $B$ cell subset (Figure 7B). These results show that the IRF5 risk haplotype does not affect expression of FcyRIIb on B cells.

We next asked whether IRF-dependent stimulation of B cells would result in haplotype-specific differences in FcyRIIb expression. B cells were stimulated with CpG or R848 for up to $40 \mathrm{~h}$, and FcyRIIb transcript and protein expression were measured by qPCR and flow cytometry, respectively. CpG and R848 stimulation both resulted in significant decreases in Fc $\gamma$ RIIb mRNA expression as early as $5 \mathrm{~h}$ after stimulation (Figure 8A). Surprisingly, protein expression remained unaffected and increased slightly at 24 and $40 \mathrm{~h}$ after R848 stimulation (Figure 8C). Although statistically significant, the changes in protein we observed in R848 stimulated B cells were very small and it is uncertain whether changes of this magnitude are enough to affect the biology of B cells. There were no haplotype-specific effects on mRNA or protein levels (Figures 8B,D). Considering IRF5 expression is low in B cells, we next sought to determine whether overexpressing IRF5 in B cells would have a measureable effect on expression of FcyRIIb. We hypothesized that overexpressing IRF5 would result in a decrease in FcyRIIb, similar to the negative regulation seen in mice (20). First we assessed expression of FcyRIIb in the Ramos, Raji, and Daudi human B cell lines (Figure 9A). We chose to utilize Raji and Daudi cells, as both expressed significant levels of FcyRllb. We cotransfected Raji and Daudi cells with a CFP reporter plasmid and either an IRF5 or empty (mock) plasmid. We isolated $\mathrm{CFP}^{+}$cells (Figure 9B, center left) and analyzed IRF5 transcript (Figure 9C, top center left and far left) and protein (Figure 9B, center right and Figure 9C, top center right and far right) and Fc $\gamma$ RIIb transcript (Figure 9C, bottom center left and far left) and protein (Figure 9B, far right and Figure 9C, bottom center right and far right) levels. We confirmed an increase in IRF5 mRNA and protein, but expression of FcyRIIb RNA and protein was unchanged.

To determine whether stimulation of the transfected cells was necessary to activate the overexpressed IRF5, transfected cells were stimulated with CpG or R 848 for $24 \mathrm{~h}$ and analyzed by flow cytometry. Activation of overexpressed IRF5 did not affect FcyRIIb expression (Figure 9D). These findings show that overexpressing or activating IRF5 does not affect Fc $\gamma$ RIIb expression in human B cells.

\section{The IRF5 Promoter Risk indel Results in Increased SP1 Binding and IRF5 Transcription in Myeloid Cells}

We decided to assess the strength of the IRF5 promoter containing either three or four repeats of the 5 bp CGGGG sequence in various cell lines: myeloid, T cell, and B cell lines. Previous work has shown increased IRF5 expression with the risk indel in ex vivo PBMCs and in HEK293 cells using a minigene assay (32). We created two Firefly luciferase reporter plasmids; one with the three repeats of CGGGG and one with four repeats, and used normalizing Renilla luciferase plasmid under control of the constitutive HSV-TK promoter. Ramos, Raji, Daudi, Jurkat, and THP-1 cells were transfected and analyzed for relative luciferase light units (Figure 10A, left). The basal level of IRF5 transcription is highest in THP-1 cells. The fold change in IRF5 transcription was also highest in THP-1 cells, as was induction of IRF5 transcription (Figure 10A, center).

Four repeats of the 5 bp CGGGG sequence in the risk haplotype introduce another binding site for the transcription factor SP1 (32). We asked whether SP1 binding to this additional site has a role in increased transcription of IRF5. To this end, we created an additional $4 \times$ indel IRF5 promoter-Firefly luciferase plasmid, with one SP1 binding site mutated to a non-SP1 binding site. We transfected THP-1 cells with the mutated plasmid and
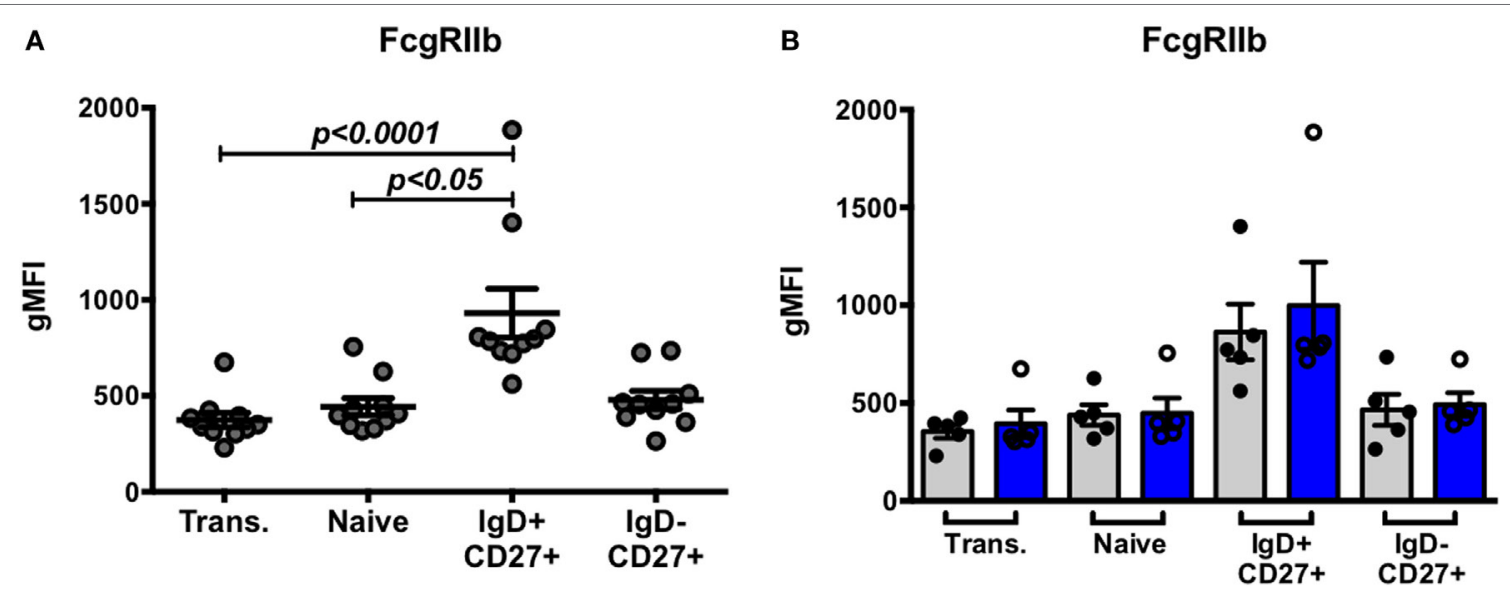

FIGURE 7 | Interferon regulatory factor 5 risk alleles do no affect baseline FcyRIllb expression in B cell subsets. B cell subsets were analyzed similarly as in Figure $\mathbf{1}$ (A) Flow cytometric results of FcyRllb protein expression in combined B cell subsets and (B) separated by haplotype. $p<0.05$ and $p<0.0001$ by Friedman test with Dunn's multiple comparisons test $\mathbf{( A )}, p=$ ns by Mann-Whitney test for each B cell subset (B). 
compared the results to the $3 \times$ and $4 \times$ indel promoter reporter plasmids. We hypothesized that if SP1 were important for the observed increased IRF5 transcription seen with the $4 \times$ indel, abolishing the additional binding site would result in luciferase readings similar to those obtained with the $3 \times$ promoter reporter plasmid. Interestingly, this result was obtained in THP-1 cells (Figure 10A, right). Thus, the SP1 transcription factor has a role in the increased transcription of the IRF5 risk haplotype observed in myeloid cells.
We next decided to assess binding of nuclear transcription factors from B cell lines and THP- 1 cells to the $3 \times$ and $4 \times$ indel. Cell lysates were incubated with infrared-labeled oligonucleotides containing three or four repeats of CGGGG and analyzed by EMSA. A specific band was observed when the $4 \times$ indel was incubated with THP-1 nuclear extracts compared with extracts of the $\mathrm{B}$ cell lines (Figure 10B, left). The banding pattern was also present in Raji extract with the $4 \times$ indel, albeit very faintly. To ask whether the binding pattern observed in THP-1 cells was due to
A

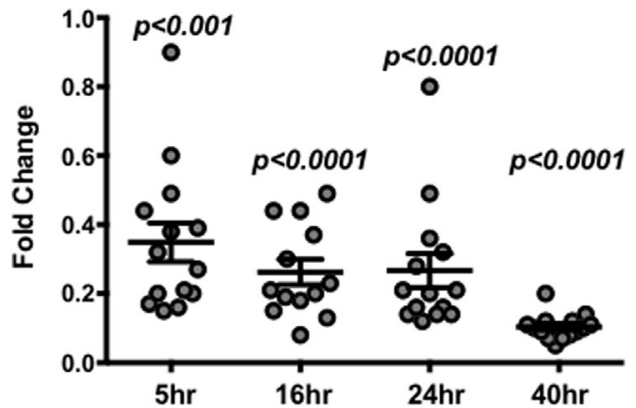

B

FCGR2B: $5 \mathrm{hrs}$

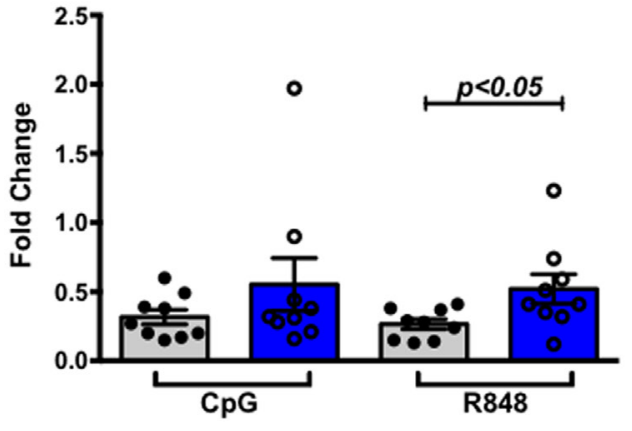

FCGR2B: $24 \mathrm{hrs}$

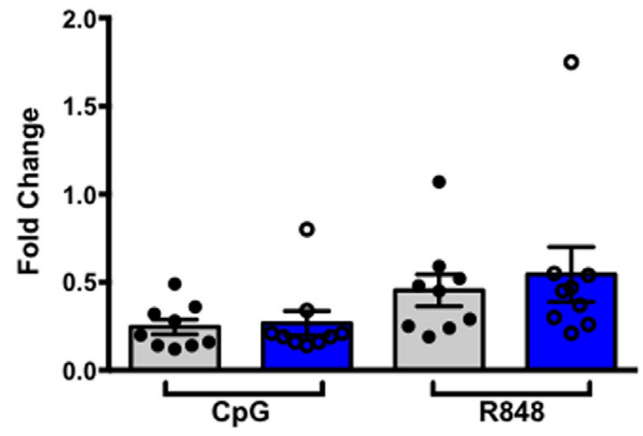

FCGR2B: R848

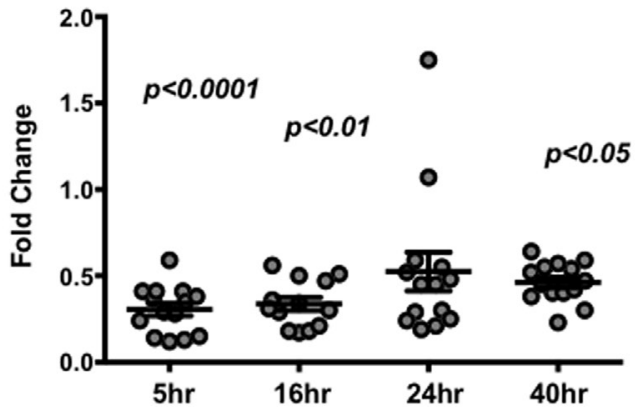

FCGR2B: 16hrs
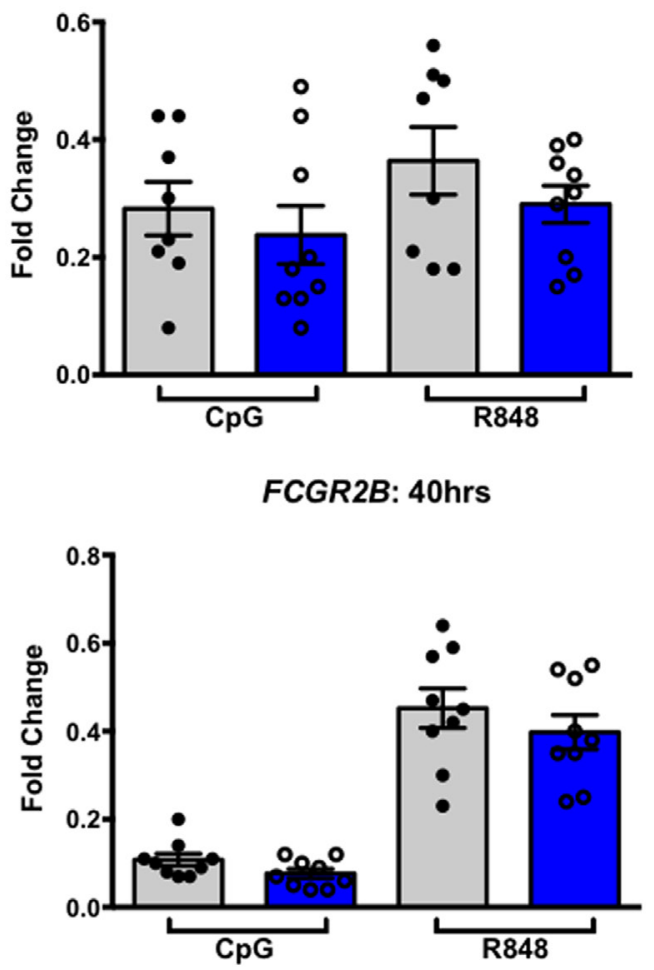

FIGURE 8 | Continued 
C

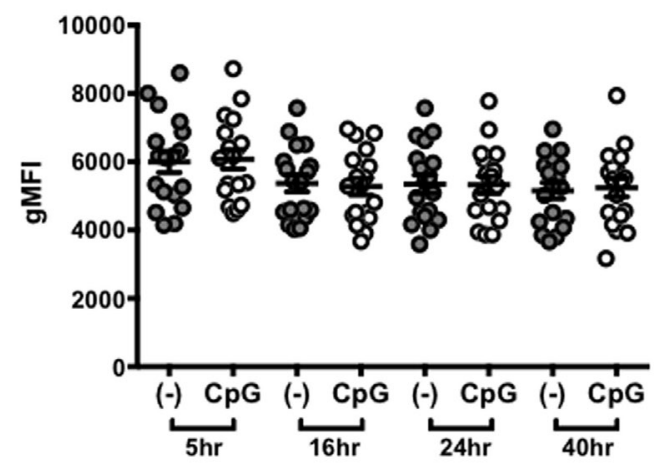

D

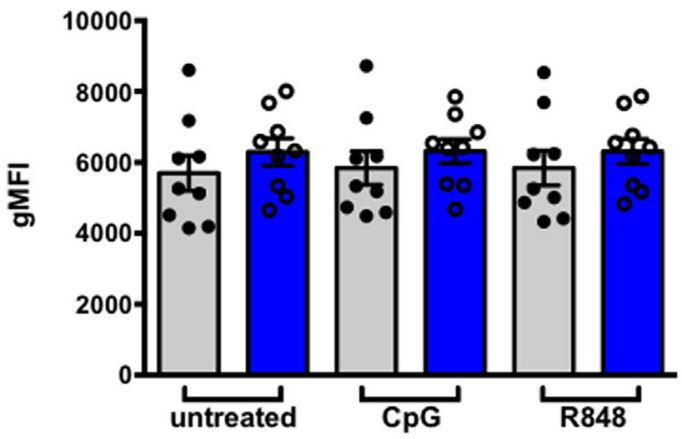

FcgRIlb: 24hrs

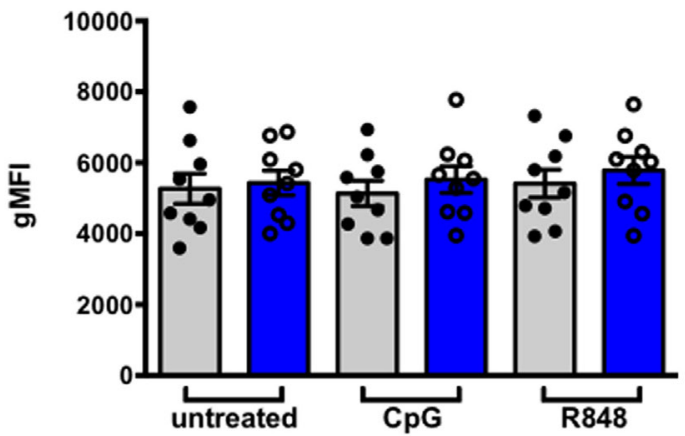

FcgRIIb: R848

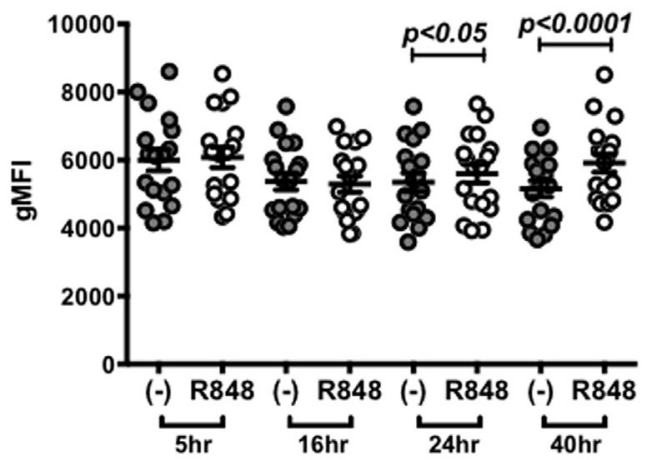

FcgRIlb: 16hrs

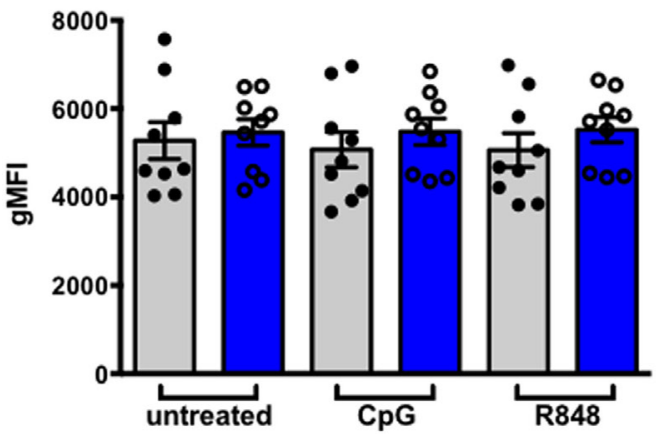

FcgRIlb: 40hrs

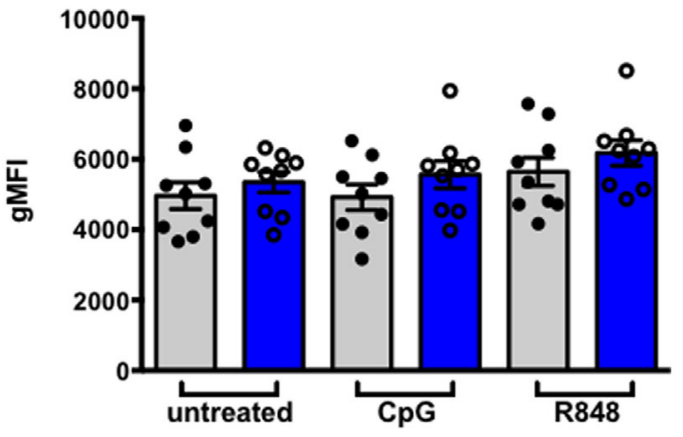

$\square$ Nonrisk

Risk

FIGURE 8 | Interferon regulatory factor 5 activation does not affect FcyRlllb expression in B cells. (A,B) FcyRlllb mRNA expression in B cells treated with CpG (right) or R848 (left) for the indicated times. Results are combined (A) and separated by haplotype (B). (C,D) FcyRlllb protein expression in B cells treated with CpG (right) or R848 (left) for the indicated time. Results are combined (C) and separated by haplotype (D). All unstimulated cell expression values are normalized to 1.0. $p<0.05$, $p<0.01, p<0.001$, and $p<0.0001$ by Friedman test with Dunn's multiple comparisons test $\mathbf{( A , C )}, p=$ ns by Mann-Whitney test for each treatment (B,D).

SP1, we performed a supershift EMSA with anti-SP1 antibody. Interestingly, we observed a change in the pattern when cell lysates were incubated with anti-SP1 (Figure 10B, right). We then asked if this is due to higher IRF5 and SP1 expression in THP-1 cells compared with B cell lines. We observed that both IRF5 and
SP1 (Figure 10C) mRNA levels were higher in THP-1 cells than in $\mathrm{B}$ cell lines. The data suggest that the differential expression of SP1 in monocytes and B cells is responsible for the haplotypespecific increased expression of IRF5 observed in myeloid cells and not in B cells. 

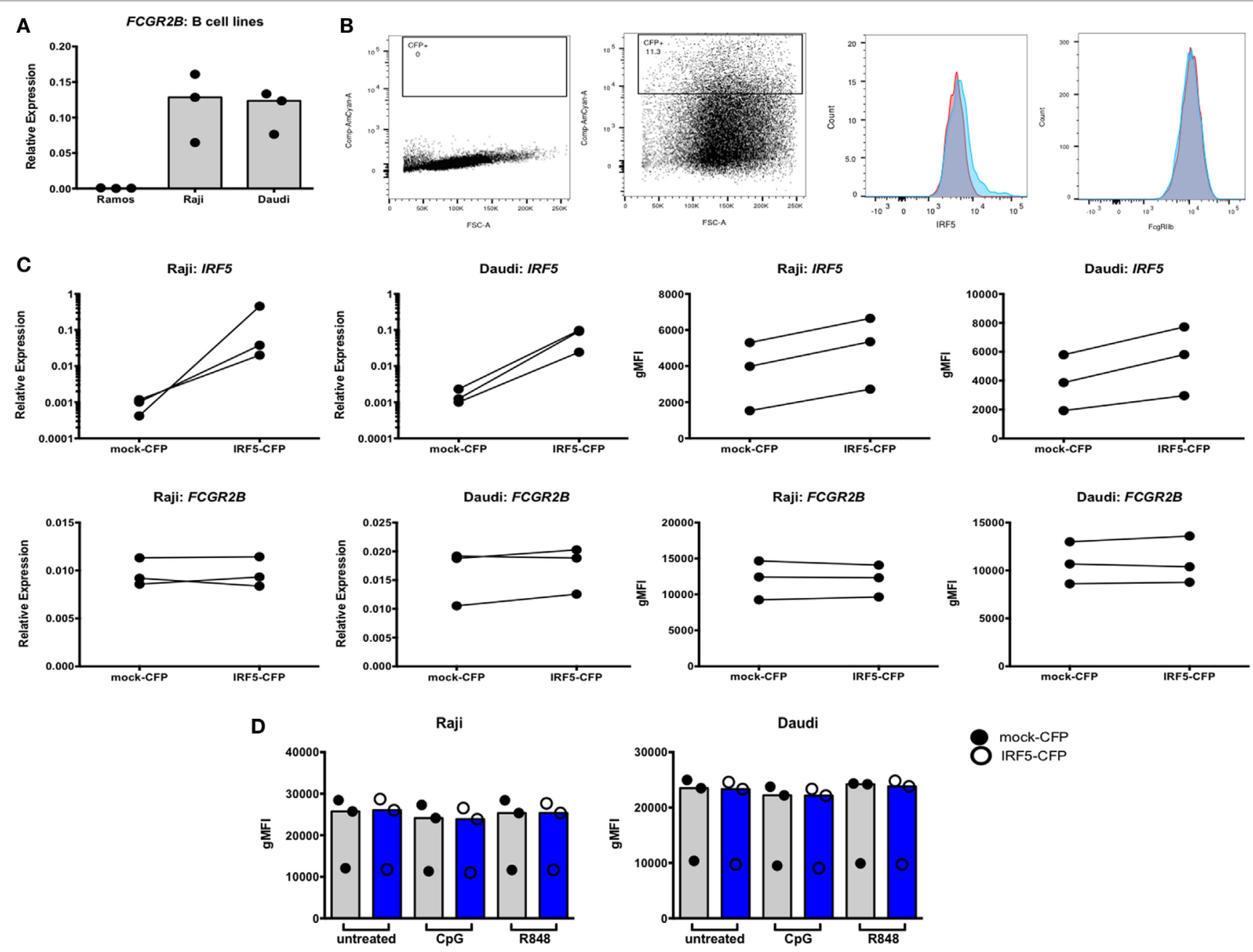

8 mock-CFP

FIGURE 9 | Interferon regulatory factor 5 (IRF5) overexpression does not affect Fc $\gamma$ Rllb expression in Raji and Daudi cells. (A) FcyRIlb expression in Ramos, Raji, and Daudi cells. (B) Representative flow cytometric data showing untransfected (far left) and transfected (center left) cells. Gated cells were used for sorting and analyses. Representative histogram of IRF5 protein expression on mock (red) and IRF5 (blue) transfected cells (center right), representative histogram of Fc $\gamma$ RIIlb protein expression on mock (red) and IRF5 (blue) transfected cells (far right). (C) IRF5 mRNA (top row, far left and left) and protein (top row, far right and right) levels in CFP ${ }^{+}$cells. FcyRllb mRNA (bottom row, far left and left) and protein (bottom row, far right and right) levels in CFP+ cells. (D) FcyRllb protein levels in CFP+ cells stimulated with CpG or R848 for $24 \mathrm{~h}$. All data shown are representative of three independent experiments.

\section{DISCUSSION}

Approximately 100 genes have been identified in GWAS of SLE (41); however, the functionality of the majority of the risk alleles has not been elucidated. The goal of this study was to define an SLE-associated IRF5 risk haplotype and determine the effects of the risk haplotype on the biology of B cells. We first defined a risk haplotype common to various populations that included the $4 \times$ CGGGG indel in the promoter region and two risk SNPs, rs10954213 and rs2004640. Our major findings were (1) the IRF5 risk haplotype does not affect quantitative IRF5 expression in resting or activated B cells, (2) IRF5 activation triggers CD86 upregulation and differentiates B cells into IgM ASCs, but this is not influenced by IRF5 haplotype, (3) IRF5 does not regulate Fc $\gamma$ RIIb in human B cells, (4) the IRF5 risk haplotype differentially affects IRF5-mediated apoptosis in monocytes and not in B cells, and (5) the transcription factor SP1 binds more strongly to the $4 \times$ CGGGG indel in myeloid cells and not in B cells. Collectively, our findings suggest that genetic risk haplotypes need to be understood in the context of cell lineage-specific functionality. Thus, somewhat unexpectedly, in the case of B cells and based on our assays cell intrinsic effects of IRF5 haplotypes do not appear to be an important factor in risk for SLE. This, of course, does not rule out cell intrinsic effects that we have not studied and cell extrinsic effects of IRF5 haplotypes on B cell function, mediated perhaps through myeloid cell lineages (42).

We note that the literature provides some evidence that contrasts with our findings. In particular, the original definition of the IRF5 haplotypic diversity by Graham et al. showed that SLE risk alleles regulate expression of IRF5 in B lymphoblastoid cell lines. This was most clearly demonstrated for the rs10954213 allele that also regulates the formation of the short and long forms 


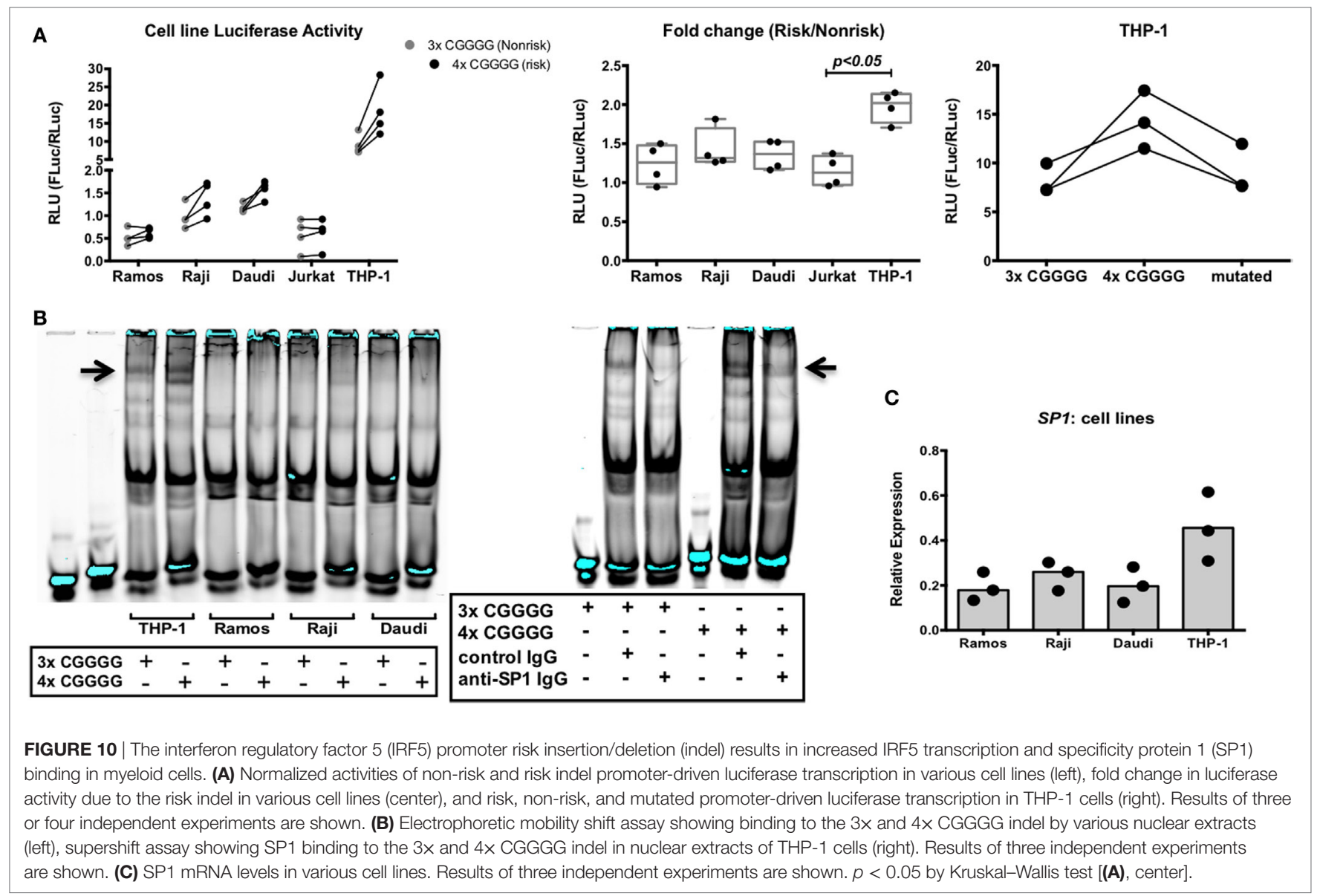

of the polyA tail of IRF5. Overall gene expression was assessed with Northern blot analysis or using microarray data in public databases, whereas our studies have utilized a TaqMan assay that is directed to the exon $2-3$ boundary. Thus, it is possible that these two approaches may give different results in terms of overall quantitation of message due to differences in mRNA isoforms. Our approach to mRNA quantitation may have missed quantitative differences in the various mRNA splice variants that are encoded the risk and non-risk haplotypes. It is also possible that $\mathrm{B}$ cell lines have regulatory mechanisms that differ from native $B$ cell populations. Nevertheless, our data strongly suggest that if mRNA splicing differences do exist between the risk and non-risk haplotypes, they do not substantially affect the B cell functional assays we have described here. Therefore, regardless of the mechanism, differences in haplotype transcriptional patterns do not appear to have a cell intrinsic effect on the critical B cell functions that we have investigated. It may well be that transcript isoforms do play some role in B cell functions that we have not examined, but our data address the major mechanisms that have been reported to be associated with B cell abnormalities in lupus.

These data emphasize the level of complexity that must be considered when trying to understand gene association studies with disease related phenotypes, namely that a gene may serve a critical purpose in a particular cell type, but a risk haplotype may or may not function differently from the non-risk haplotype in that cell type. The chain of causation in autoimmune diseases such as SLE clearly involves complex cell-cell interactions. The data reported here strongly suggest that the influence of IRF5 on B cell abnormalities is likely to depend to a large degree on the effects of IRF5 on cells which have a regulatory role on B cell function, such as myeloid cells. Further functional studies of IRF5 can profitably be focused on this possibility.

\section{ETHICS STATEMENT}

The protocol was approved by the IRB of Northwell Health All subjects gave written informed consent in accordance with the Declaration of Helsinki.

\section{AUTHOR CONTRIBUTIONS}

JC: performed experiments, analyzed data, designed experiments, and wrote and edited manuscript. SR: built IRF5 haplotypes from 1000 Genomes data. PG: GAP and Biorepository leader, provided GAP samples and DNA for genotyping, and edited manuscript. BD: designed experiments, analyzed data, and edited manuscript.

\section{ACKNOWLEDGMENTS}

We are very grateful for the volunteers in the GAP Registry who participated in this study making it possible, as well as the coordinators of the GAP for recruiting subjects and obtaining samples: 
Margaret DeFranco, Gila Klein, Mushmoom Khan, and Mary Keogh. We thank Herb Borrero and Chris Colon of the Flow Cytometry Core Facility for technical assistance, Mike Ryan of the FIMR Biorepository for GAP subject DNA, and Marty Lesser of the Biostatistics Unit of the FIMR for statistical assistance. We thank Jonothan Logan for assistance with molecular cloning and the following people for valuable discussions pertaining to this

\section{REFERENCES}

1. Sigurdsson S, Nordmark G, Goring HH, Lindroos K, Wiman AC, Sturfelt G, et al. Polymorphisms in the tyrosine kinase 2 and interferon regulatory factor 5 genes are associated with systemic lupus erythematosus. Am J Hum Genet (2005) 76:528-37. doi:10.1086/428480

2. Graham RR, Kozyrev SV, Baechler EC, Reddy MV, Plenge RM, Bauer JW, et al. A common haplotype of interferon regulatory factor 5 (IRF5) regulates splicing and expression and is associated with increased risk of systemic lupus erythematosus. Nat Genet (2006) 38:550-5. doi:10.1038/ng1782

3. Krausgruber T, Blazek K, Smallie T, Alzabin S, Lockstone H, Sahgal N, et al. IRF5 promotes inflammatory macrophage polarization and TH1-TH17 responses. Nat Immunol (2011) 12:231-8. doi:10.1038/ni.1990

4. Mancl ME, Hu G, Sangster-Guity N, Olshalsky SL, Hoops K, FitzgeraldBocarsly P, et al. Two discrete promoters regulate the alternatively spliced human interferon regulatory factor-5 isoforms. Multiple isoforms with distinct cell type-specific expression, localization, regulation, and function. J Biol Chem (2005) 280:21078-90. doi:10.1074/jbc.M500543200

5. Krausgruber T, Saliba D, Ryzhakov G, Lanfrancotti A, Blazek K, Udalova IA. IRF5 is required for late-phase TNF secretion by human dendritic cells. Blood (2010) 115:4421-30. doi:10.1182/blood-2010-01-263020

6. Barnes BJ, Moore PA, Pitha PM. Virus-specific activation of a novel interferon regulatory factor, IRF-5, results in the induction of distinct interferon alpha genes. J Biol Chem (2001) 276:23382-90. doi:10.1074/jbc.M101216200

7. Barnes BJ, Kellum MJ, Pinder KE, Frisancho JA, Pitha PM. Interferon regulatory factor 5, a novel mediator of cell cycle arrest and cell death. Cancer Res (2003) 63:6424-31.

8. Hedl M, Yan J, Abraham C. IRF5 and IRF5 disease-risk variants increase glycolysis and human M1 macrophage polarization by regulating proximal signaling and Akt2 activation. Cell Rep (2016) 16:2442-55. doi:10.1016/j. celrep.2016.07.060

9. Kirou KA, Lee C, George S, Louca K, Papagiannis IG, Peterson MG, et al. Coordinate overexpression of interferon-alpha-induced genes in systemic lupus erythematosus. Arthritis Rheum (2004) 50:3958-67. doi:10.1002/art. 20798

10. Feng X, Wu H, Grossman JM, Hanvivadhanakul P, FitzGerald JD, Park GS, et al. Association of increased interferon-inducible gene expression with disease activity and lupus nephritis in patients with systemic lupus erythematosus. Arthritis Rheum (2006) 54:2951-62. doi:10.1002/art.22044

11. Baechler EC, Batliwalla FM, Karypis G, Gaffney PM, Ortmann WA, Espe KJ, et al. Interferon-inducible gene expression signature in peripheral blood cells of patients with severe lupus. Proc Natl Acad Sci U S A (2003) 100:2610-5. doi:10.1073/pnas.0337679100

12. Bennett L, Palucka AK, Arce E, Cantrell V, Borvak J, Banchereau J, et al. Interferon and granulopoiesis signatures in systemic lupus erythematosus blood. J Exp Med (2003) 197:711-23. doi:10.1084/jem.20021553

13. Feng D, Stone RC, Eloranta ML, Sangster-Guity N, Nordmark G, Sigurdsson S, et al. Genetic variants and disease-associated factors contribute to enhanced interferon regulatory factor 5 expression in blood cells of patients with systemic lupus erythematosus. Arthritis Rheum (2010) 62:562-73. doi:10.1002/ art. 27223

14. Hedl M, Abraham C. IRF5 risk polymorphisms contribute to interindividual variance in pattern recognition receptor-mediated cytokine secretion in human monocyte-derived cells. J Immunol (2012) 188:5348-56. doi:10.4049/ jimmunol.1103319

15. Lien C, Fang CM, Huso D, Livak F, Lu R, Pitha PM. Critical role of IRF-5 in regulation of B-cell differentiation. Proc Natl Acad Sci U S A (2010) 107:4664-8. doi:10.1073/pnas.0911193107 study: Kim R. Simpfendorfer, Jolien Suurmond, Sun Jung Kim, and Susan Malkiel.

\section{FUNDING}

This work was supported by the National Institutes of Health Grant \#1R21AR067012-01A1 (to BD).

16. Yasuda K, Watkins AA, Kochar GS, Wilson GE, Laskow B, Richez C, et al. Interferon regulatory factor-5 deficiency ameliorates disease severity in the MRL/lpr mouse model of lupus in the absence of a mutation in DOCK2. PLoS One (2014) 9:e103478. doi:10.1371/journal.pone.0103478

17. Yasuda K, Nundel K, Watkins AA, Dhawan T, Bonegio RG, Ubellacker JM, et al. Phenotype and function of B cells and dendritic cells from interferon regulatory factor 5-deficient mice with and without a mutation in DOCK2. Int Immunol (2013) 25:295-306. doi:10.1093/intimm/dxs114

18. Savitsky DA, Yanai H, Tamura T, Taniguchi T, Honda K. Contribution of IRF5 in B cells to the development of murine SLE-like disease through its transcriptional control of the IgG2a locus. Proc Natl Acad Sci U S A (2010) 107:10154-9. doi:10.1073/pnas.1005599107

19. Tada Y, Kondo S, Aoki S, Koarada S, Inoue H, Suematsu R, et al. Interferon regulatory factor 5 is critical for the development of lupus in MRL/lpr mice. Arthritis Rheum (2011) 63:738-48. doi:10.1002/art.30183

20. Panchanathan R, Liu H, Liu H, Fang CM, Erickson LD, Pitha PM, et al. Distinct regulation of murine lupus susceptibility genes by the IRF5/Blimp-1 axis. J Immunol (2012) 188:270-8. doi:10.4049/jimmunol.1102311

21. Avalos AM, Uccellini MB, Lenert P, Viglianti GA, Marshak-Rothstein A. FcgammaRIIB regulation of BCR/TLR-dependent autoreactive B-cell responses. Eur J Immunol (2010) 40:2692-8. doi:10.1002/eji.200940184

22. Ravetch JV, Bolland S. IgG Fc receptors. Annu Rev Immunol (2001) 19:275-90. doi:10.1146/annurev.immunol.19.1.275

23. Bolland S, Ravetch JV. Inhibitory pathways triggered by ITIM-containing receptors. Adv Immunol (1999) 72:149-77. doi:10.1016/S0065-2776(08)60019-X

24. Choubey D, Panchanathan R. Interferon-inducible Ifi200-family genes in systemic lupus erythematosus. Immunol Lett (2008) 119:32-41. doi:10.1016/j. imlet.2008.06.001

25. Lazzari E, Jefferies CA. IRF5-mediated signaling and implications for SLE. Clin Immunol (2014) 153:343-52. doi:10.1016/j.clim.2014.06.001

26. Clark DN, Read RD, Mayhew V, Petersen SC, Argueta LB, Stutz LA, et al. Four promoters of IRF5 respond distinctly to stimuli and are affected by autoimmune-risk polymorphisms. Front Immunol (2013) 4:360. doi:10.3389/ fimmu.2013.00360

27. Alonso-Perez E, Suarez-Gestal M, Calaza M, Kwan T, Majewski J, GomezReino JJ, et al. Cis-regulation of IRF5 expression is unable to fully account for systemic lupus erythematosus association: analysis of multiple experiments with lymphoblastoid cell lines. Arthritis Res Ther (2011) 13:R80. doi:10.1186/ $\operatorname{ar} 3343$

28. Clark DN, Lambert JP, Till RE, Argueta LB, Greenhalgh KE, Henrie B, et al. Molecular effects of autoimmune-risk promoter polymorphisms on expression, exon choice, and translational efficiency of interferon regulatory factor 5 . J Interferon Cytokine Res (2014) 34:354-65. doi:10.1089/jir.2012.0105

29. Kozyrev SV, Lewen S, Reddy PM, Pons-Estel B; Argentine Collaborative Group, Witte T, et al. Structural insertion/deletion variation in IRF5 is associated with a risk haplotype and defines the precise IRF5 isoforms expressed in systemic lupus erythematosus. Arthritis Rheum (2007) 56:1234-41. doi:10.1002/art.22497

30. Graham RR, Kyogoku C, Sigurdsson S, Vlasova IA, Davies LR, Baechler EC, et al. Three functional variants of IFN regulatory factor 5 (IRF5) define risk and protective haplotypes for human lupus. Proc Natl Acad Sci U S A (2007) 104:6758-63. doi:10.1073/pnas.0701266104

31. Cunninghame Graham DS, Manku H, Wagner S, Reid J, Timms K, Gutin A, et al. Association of IRF5 in UK SLE families identifies a variant involved in polyadenylation. Hum Mol Genet (2007) 16:579-91. doi:10.1093/hmg/ dd1469

32. Sigurdsson S, Goring HH, Kristjansdottir G, Milani L, Nordmark G, Sandling JK, et al. Comprehensive evaluation of the genetic variants of 
interferon regulatory factor 5 (IRF5) reveals a novel 5 bp length polymorphism as strong risk factor for systemic lupus erythematosus. Hum Mol Genet (2008) 17:872-81. doi:10.1093/hmg/ddm359

33. Guthridge JM, Clark DN, Templeton A, Dominguez N, Lu R, Vidal GS, et al. Effects of IRF5 lupus risk haplotype on pathways predicted to influence B cell functions. J Biomed Biotechnol (2012) 2012:594056. doi:10.1155/2012/594056

34. Islam KB, Baskin B, Christensson B, Hammarstrom L, Smith CI. In vivo expression of human immunoglobulin germ-line mRNA in normal and in immunodeficient individuals. Clin Exp Immunol (1994) 95:3-9. doi:10.1111/ j.1365-2249.1994.tb06006.x

35. Veri MC, Gorlatov S, Li H, Burke S, Johnson S, Stavenhagen J, et al. Monoclonal antibodies capable of discriminating the human inhibitory Fcgammareceptor IIB (CD32B) from the activating Fcgamma-receptor IIA (CD32A): biochemical, biological and functional characterization. Immunology (2007) 121:392-404. doi:10.1111/j.1365-2567.2007.02588.x

36. Genomes Project C, Auton A, Brooks LD, Durbin RM, Garrison EP, Kang HM, et al. A global reference for human genetic variation. Nature (2015) 526: 68-74. doi:10.1038/nature15393

37. Meffre E, Wardemann H. B-cell tolerance checkpoints in health and autoimmunity. Curr Opin Immunol (2008) 20:632-8. doi:10.1016/j.coi.2008.09.001

38. Hu G, Mancl ME, Barnes BJ. Signaling through IFN regulatory factor-5 sensitizes p53-deficient tumors to DNA damage-induced apoptosis and cell death. Cancer Res (2005) 65:7403-12. doi:10.1158/0008-5472.CAN05-0583

39. Farrant J. Germ-line transcripts and class switching. Clin Exp Immunol (1994) 95:1-2. doi:10.1111/j.1365-2249.1994.tb06005.x

40. Mackay M, Stanevsky A, Wang T, Aranow C, Li M, Koenig S, et al. Selective dysregulation of the FcgammaIIB receptor on memory B cells in SLE. J Exp Med (2006) 203:2157-64. doi:10.1084/jem.20051503

41. Deng Y, Tsao BP. Advances in lupus genetics and epigenetics. Curr Opin Rheumatol (2014) 26:482-92. doi:10.1097/BOR.0000000000000086

42. Suurmond J, Calise J, Malkiel S, Diamond B. DNA-reactive B cells in lupus. Curr Opin Immunol (2016) 43:1-7. doi:10.1016/j.coi.2016.07.002

Conflict of Interest Statement: The authors declare that the research was conducted in the absence of any commercial or financial relationships that could be construed as a potential conflict of interest.

Copyright $@ 2018$ Calise, Marquez Renteria, Gregersen and Diamond. This is an openaccess article distributed under the terms of the Creative Commons Attribution License (CC BY). The use, distribution or reproduction in other forums is permitted, provided the original author(s) and the copyright owner are credited and that the original publication in this journal is cited, in accordance with accepted academic practice. No use, distribution or reproduction is permitted which does not comply with these terms. 